\title{
Progress in CTBT Monitoring Since its 1999 Senate Defeat
}

\section{David Hafemeister}

Center for International Security and Cooperation, Stanford University, Stanford, CA, USA

Progress in monitoring the Comprehensive Nuclear Test Ban Treaty (CTBT) is examined, beginning with the 2002 National Academy of Sciences CTBT study, followed by recent findings on regional seismology, array-monitoring, correlation-detection, seismic modeling, and non-seismic technologies. The NAS-CTBT study concluded that the fully completed International Monitoring System (IMS) will reliably detect and identify underground nuclear explosions with a threshold of $0.1 \mathrm{kt}$ in hard rock, if conducted anywhere in Europe, Asia, North Africa, and North America. In some locations the threshold is $0.01 \mathrm{kt}$ or lower, using arrays or regional seismic stations, but with an increase in background events. As an example, the 0.6-kiloton North Korean test of October 9, 2006 was promptly detected by seismometers in Australia, Europe, North America, and Asia. The $\mathrm{P} / \mathrm{S}$ ratio between $1-15 \mathrm{~Hz}$ clearly showed that the event was an explosion and not an earthquake. The advances in seismic monitoring, described in this article, strengthen the conclusions of the NAS study. Interferometric synthetic aperture radar can, in some cases, identify and locate $1-\mathrm{kt}$ tests at $500 \mathrm{~m}$ depth by measuring subsidence to $2-5 \mathrm{~mm}$. InSAR can discriminate between earthquakes and explosions from the subsidence pattern. InSAR will not give a rapid response, but InSAR can locate nuclear tests to within 100 meters, excellent for on-site inspections. Cooperative monitoring can detect yields of $10 \mathrm{~kg}$ next to a test site and less than a gram when two meters from experiments without revealing nuclear secrets.

\section{INTRODUCTION}

The Comprehensive Nuclear Test Ban Treaty (CTBT) bans all nuclear explosions (including peaceful nuclear explosions) of any yield in all places for all time. The United States signed the CTBT in 1996, but the U.S. Senate denied 
advice and consent to CTBT ratification in 1999. One factor in the Senate debate was concern on how well a test ban could be monitored. This article discusses progress in monitoring technologies since the 1999 Senate defeat. These results will be used to determine whether the CTBT is effectively verifiable in a future paper. $^{1}$

\section{NATIONAL ACADEMY STUDY ON CTBT}

The 2002 National Academy of Sciences CTBT Study examined the ability of the CTBT International Monitoring System (IMS) to monitor seismic, infrasound, hydroacoustic, and radionuclide signals. ${ }^{2,3}$ Of these, seismic detection is the most important, but the other sensors make significant contributions.

\section{Improvements in Seismic Monitoring}

Seismic signals are grouped into teleseismic waves and regional waves, depending on the observation distance. Teleseismic waves propagate as body waves through the interior of the earth-through the crust into the mantle and back through the crust_-at distances greater than $2000 \mathrm{~km}$ at higher frequencies $(0.2$ to $3 \mathrm{~Hz})$, or as low frequency $(0.05 \mathrm{~Hz})$ surface waves. Amplitudes of teleseismic waves are not greatly diminished at distances between 2000 and $9000 \mathrm{~km}$, making them suitable to measure events outside country borders. The longitudinal, pressure $\mathrm{P}$ waves are readily excited by explosions and they arrive first. The transverse, shear $\mathrm{S}$ waves are readily excited by earthquakes and arrive after the $\mathrm{P}$ wave. NAS results were based on the ability to monitor both teleseismic waves and regional waves at closer distances.

The seismic $m_{b}$ magnitude is based on the initial amplitude of 1-Hertz, pressure waves, which is used to estimate yield in kilotons (kt). To first order a 1-kt explosion, tamped in hard rock, has a magnitude of about 4 at the Nevada Test Site. Geological strata absorb seismic waves differently, thus different bias corrections are needed for each test site when converting magnitudes to yields. ${ }^{4}$ Progress in seismology has lowered the problem-event threshold by two magnitude $\mathrm{m}_{\mathrm{b}}$ units, from 4.3-5.6 thirty years ago to 2.0-3.5 today, lowering problemevent yields by a factor of more than 100.5 With the advent of high-quality broadband seismographs and more seismic stations, seismic research is now focused on regional seismic waves that travel on the surface and in the crust. Advances in regional seismology, discussed in more detail in later sections, convinced the NAS panel to lower the IMS threshold detection level from $1 \mathrm{kt}$ to $0.1 \mathrm{kt}$, which clearly enhances CTBT monitoring. Lower magnitude events imply lower yields, which are less militarily significant.

The lowered threshold also brings with it an increase in background events, from 7000 earthquakes per year over magnitude 4 to 60,000 per year over magnitude 3. Several criteria are used to distinguish explosions from 
earthquakes. For one, most of the events can be ruled out because they take place below the oceans or at great depths. The ratio of $\mathrm{P}$ to $\mathrm{S}$ waves and other considerations can further discriminate, as discussed in Regional Seismology Monitoring.

NAS-CTBT conclusions are based on a completed International Monitoring System, called for by the CTBT. The IMS plan and status today are discussed in more detail in the section International Monitoring System. In summary, the IMS will consist of 321 monitoring stations for seismic (50 primary and 120 auxiliary), hydroacoustic (11), radionuclide (80), and infrasound (60) sensors, together with 16 certified laboratories. IMS seismic stations use broadband sensors that detect both teleseismic body waves at lower frequencies and regional waves at higher frequencies, increasing the ability to make spectral comparisons to enhance source discrimination. Digital records are obtained for motion in three directions (up/down, north/south, east/west). Of the 50 primary IMS stations, 19 will use triple-axis sensors and 30 will use arrays of verticalmotion sensors. The arrays consist of 9 to 25 sensors, spread over several square kilometers. Estimates of the network threshold depend on local seismic noise, sensor type and quality, magnitude and type of seismic waves, and the ability to use waveform shapes to discriminate between nuclear explosions, earthquakes, and conventional (ripple-fired) chemical explosions.

Seismic threshold-detection contours from the NAS-CTBT panel are shown in Figure 1, with a signal-to-noise ratio greater than 3.2 (corresponding to 10 decibels) at three or more IMS-primary stations (solid squares). The IMS should detect 90 percent of events (high confidence, as defined by the Intelligence Community) at contour edges at the threshold magnitudes. NAS-CTBT's detection threshold for the primary network for Europe, Asia, North Africa, and North America is between 3 and $3.5 \mathrm{~m}_{\mathrm{b}}$. It is lower in places with array stations and seismographs at closer locations. Threshold levels will improve with further research on regional waves and with the addition of new technical capabilities described in this article.

The magnitude contours of Figure 1 are translated into explosive-yield contours in Figure 2, as described on page 41 of the NAS study: $3.5 \mathrm{~m}_{\mathrm{b}}(0.1 \mathrm{kt})$, $3.25(0.06 \mathrm{kt}), 3(0.03 \mathrm{kt}), 2.75(0.02 \mathrm{kt}), 2.5(0.01 \mathrm{kt}), 2(0.003 \mathrm{kt}){ }^{6}$ For most of Eurasia and North Africa this corresponds to a $0.03-0.1$ kt yield from a tamped explosion (where the nuclear device is in direct contact with hard rock). The contours are given in tons and are $90 \%$-probable for at least 3-station detection in the 50-primary stations network. Using seismic arrays, the threshold detection level at the former Soviet test site at Novaya Zemlya is between 2.0 and $2.5 \mathrm{~m}_{\mathrm{b}}$, corresponding to 0.003 to $0.01 \mathrm{kt}$. These results are consistent with other estimates: Sykes/Evernden (1982), ${ }^{7}$ Sykes, Evernden, Cifuentes (1983), ${ }^{8}$ Evernden, Archambeau (1986), ${ }^{9}$ Hannon $(1985,1988),{ }^{10}$ OTA (1988), ${ }^{11}$ Claassen, Unger, Leith (1993), ${ }^{12}$ and Provisional CTBTO Technical Secretariat (2006). ${ }^{13}$ 


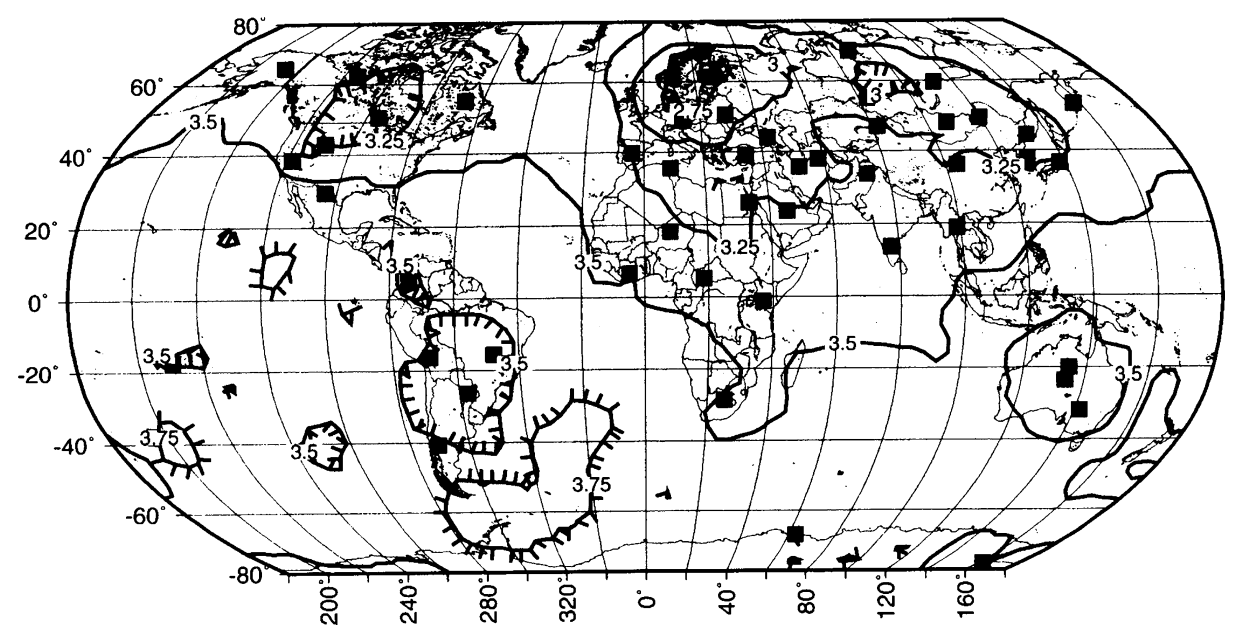

Figure 1: IMS Detection Thresholds in Seismic Units $\left(m_{b}\right)$. Contours of seismic magnitude for which signals would be expected (with signal-to-noise ratio greater than 3.2 , that is, $10 \mathrm{~dB}$ ) at three or more stations of the IMS primary seismic network (solid squares) from 90 percent of the events at the contour magnitude. The interval between contours is $0.25 \mathrm{mb}_{\mathrm{b}}$ units (Center for Monitoring Research, Nuclear Testing Programs, Department of Defense, in Technical Issues Related to the Comprehensive Nuclear Test Ban Treaty, National Academy of Sciences, National Academy Press, 2002, p. 52.).

\section{NAS-Panel Conclusions}

The NAS panel assumed that all elements of the IMS are deployed and supported at their full capability:

- Underground explosions can be detected and can be identified as explosions, using IMS data, down to a yield of $0.1 \mathrm{kt}$ [tamped] in hard rock if conducted anywhere in Europe, Asia, North America, and North Africa. In some locations of interest, such as Novaya Zemlya, this capability extends down to $0.01 \mathrm{kt}$ or less. Depending on the medium in which the identified explosion occurs, its actual yield could vary from the hard rock value over a range given by multiplying or dividing by a factor of about 10 , corresponding, respectively, to the extremes represented by a test in deep unconsolidated dry sediments (very poor coupling) and a test in a water-saturated environment (excellent coupling). Positive identification as a nuclear explosion, for testing less than a few kilotons, could require on-site inspection unless there is detectable venting of radionuclides. Attribution would likely be unambiguous.

- Atmospheric explosions can be detected and identified as nuclear, using IMS data, with high confidence above $0.5 \mathrm{kt}$ on continents in the northern hemisphere and above $1 \mathrm{kt}$ worldwide, and possibly at much lower yields for many sub-regions. Although attribution could be difficult based on IMS data alone, evaluation of other information (including that obtained by National Technical Means (NTM)) could permit an unambiguous determination. 


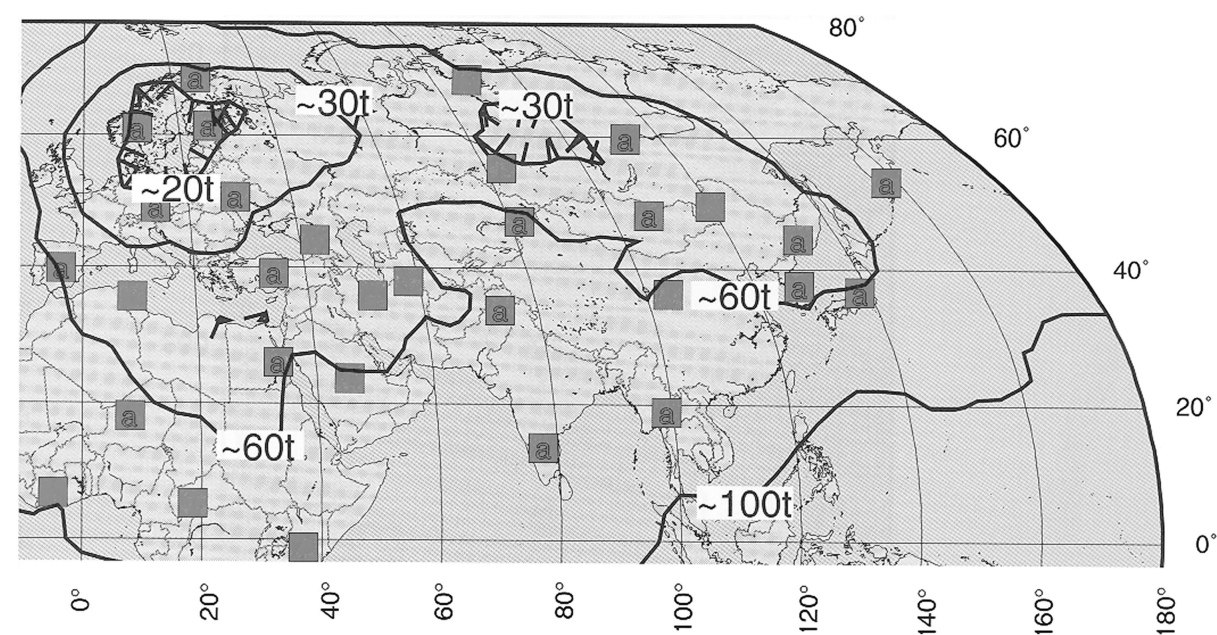

Figure 2: IMS Detection Thresholds in Explosive Yield (tons). Contours of approximate yield in tons for tamped explosions, for which detection is expected at three IMS primary stations (solid squares). These contours are determined from the magnitude contours in Figure 1, but with an expanded view of Europe, Asia, and North Africa. (DOD/CMR)

- Underwater explosions in the ocean can be reliably detected and identified as explosions using IMS data, at yields down to $0.001 \mathrm{kt}$ or even lower. Positive identification as a nuclear explosion could require debris collection. Attribution might be difficult to establish unless additional information was available, as it might be, from NTM.

- Explosions in the upper atmosphere and near space can be detected and identified as nuclear, with suitable instrumentation, with great confidence for yields above about a kiloton to distances up to about 100 million kilometers from Earth. (This capability is based on the assumption that relevant instruments that have been proposed for deployment on the follow-on system for the DSP satellites will in fact be funded and installed.)

- A fully-decoupled explosion of larger than 1-2 kt cannot be confidently hidden in a cavity and it would be very difficult at that level. (This will be further examined in the forthcoming paper on effective verification.)

\section{INTERNATIONAL MONITORING SYSTEM}

The last Conference on Facilitating the Entry into Force of the Comprehensive Nuclear-Test Ban Treaty took place in Vienna during September 17-18, 2007. Of the 177 states that signed as of September 2007, 106 sent delegations, including Iraq, Iran, and Pakistan, with several states represented at the Minister or Deputy Minister level. At the end of 2006, 184 of the 321 IMS stations were certified, 60 were operational but not certified, 19 were under construction, 21 
Table 1: Status of the station installation program as of December 31, 2006. (CTBTO)

\begin{tabular}{lcccccc} 
& \multicolumn{3}{l}{ Installation complete } & & Not \\
\cline { 2 - 5 } IMS station type & Certified & $\begin{array}{c}\text { Notract } \\
\text { certified }\end{array}$ & $\begin{array}{c}\text { Under } \\
\text { construction }\end{array}$ & $\begin{array}{c}\text { under } \\
\text { negotiation }\end{array}$ & $\begin{array}{c}\text { Not } \\
\text { started }\end{array}$ \\
\hline Primary seismic & $36(72 \%)$ & 6 & 2 & 2 & 4 \\
Auxiliary seismic & $61(51 \%)$ & 38 & 2 & 9 & 10 \\
Hydroacoustic & $9(82 \%)$ & 1 & 1 & 0 & 0 \\
Infrasound & $37(62 \%)$ & 1 & 4 & 6 & 12 \\
Radionuclide & $41(51 \%)$ & 14 & 10 & 4 & 11 \\
Total & 184 & 60 & 19 & 21 & 37 \\
\hline
\end{tabular}

were under negotiation, and 37 had not started (Table 1). In addition, 9 of the 16 radionuclide laboratories were certified. It is reasonable to assume that the last $10 \%$ of the stations will not be certified for a decade or so because of difficult political or geographic situations, giving a 90\%-complete IMS in perhaps 2010 .

\section{International Data Centre}

Events that have not been screened out are initially placed on the Standard Event Lists 0, 1, 2, and 3 after 0.3, 2, 6, and 12 hours, respectively. The automatic Standard Event List 3 received an average of 122 events per day in 2006 , with 76 placed on the Reviewed Event Bulletin. Waveform events (seismic, infrasound, hydroacoustic) are moved to the Reviewed and Standard Event Bulletin after 1 day and to the Standard Screened Event Bulletin after 2 days. The latency period on the Reviewed Event Bulletin is 8 days, which is greater than the 3-day goal. Computer software is being replaced at the rate of $\$ 2-4$ million per year to improve this situation. The travel time for radionuclide nuclei is 1 to 2 weeks.

\section{Communications}

The International Data Centre (IDC) sent 1,600,000 subscription data sets in 2006 to 808 end-users in 94 countries at 8 gigabytes per day. Performance tests assessed reliability and security of the IMS network and the Global Communications Infrastructure that connects IMS stations to the IDC. The main causes of problems at waveform stations were software (now being addressed), power supply, remote computers, digitizers, and data authentication. The Global Communication Infrastructure sent 8.3 gigabytes/day in 2006, which was $99.6 \%$ available (97.9\% with planned outages), with a contractual requirement of 99.5\%. As of December 2006, there were 208 very small aperture satellite terminals (84\% of the 248-planned total), with 240 site surveyed (97\%). The Provisional Technical Secretariat (PTS) uses quality 
management systems (QMS) to assess planning, monitoring, data analysis, and operations.

\section{Danger Signs}

The United States has lost its voting rights in the Preparatory Commission for the CTBTO. According to the Resolution Establishing the Preparatory Commission for the CTBTO (adopted in 1996), "a state-signatory which has not discharged in full its financial obligations within 365 days of receipt ... shall have no vote in the Commission." As of October 5, 2007, the United States was in arrears by $\$ 24$ million (M). This is partially driven by the fact that the United States will not fund on-site inspection activities because it does not wish the CTBT to enter-into-force. But the short-fall is greater than this issue, driven by those that wish to kill the CTBT. For Fiscal Year 2006, the United States contributed $\$ 14.4 \mathrm{M}$ of the $\$ 22 \mathrm{M}$ request, and for FY2007, the United States contributed $\$ 10.5 \mathrm{M}$ of the $\$ 23.4 \mathrm{M}$ request, which is exacerbated by the different fiscal years. For FY2008, the Administration budgeted $\$ 18 \mathrm{M}$ of the $\$ 23.4 \mathrm{M}$ request, which is now under consideration by the Congress. Because the United States is the largest contributor to the CTBTO, these funding shortfalls have a significant, adverse effect on the CTBTO with a budget of $\$ 110 \mathrm{M}$ for FY2007. Brazil ( $\$ 12 \mathrm{M})$ Argentina $(\$ 6.6 \mathrm{M})$ and others are also in arrears, with a total CTBTO arrears of $\$ 51 \mathrm{M}$.

The CTBT Organization has 254 staff members (286 positions), which includes 163 professional (185 positions) from 66 states. About 45 of the professional employees come from the 5 nuclear weapon states. CTBTO is reorganizing the IMS Division to do engineering and maintenance on the IMS, whereas the IDC Division will operate the IMS and analyze IMS data. As the IMS is completed, plans are beginning to be made for the next generation of technology, which is not yet budgeted. Professional employment is limited to seven years, complicating the work of IMS and IDC as talented technical staff must be replaced.

\section{System Performance}

The System Wide Performance Test (SPT1) "assesses the capacity of the functional elements currently in place, including the work processes supporting the achievement of performance targets, e.g., data availability and quality requirements, data processing and product and service delivery." SPT1 results (December 2005 with 163 certified stations and 32 primary seismic stations) showed that IMS is generally fulfilling its goals, except that the threshold for the incomplete primary network is $0.3 \mathrm{~m}_{\mathrm{b}}$ higher than the final goal in southern South America, East Asia, and Australia. ${ }^{14}$ The assessment indicated that further tools are needed (1) to log and analyze problems, (2) to monitor and analyze 
operational status, (3) to develop O\&M cost estimates, and (4) to measure IMS performance.

\section{Screening Criteria}

The IDC uses the screening criteria, listed in the following sections, to categorize events on its bulletins. The CTBT Protocol suggests additional approaches that could be used after further research. ${ }^{15} \mathrm{~A}$ parallel approach is used by the U.S. Data Center at Patrick Air Force Base, Florida, which is operated by the Air Force Technical Applications Center (AFTAC). Trained military personnel sift through data, using criteria similar to that used by the IDC. Uncertainties surrounding possible problem events consume considerable effort, including that of outside experts.

\section{$m_{b}$ Threshold}

A threshold of 3.0-3.3 for the IDC is used at this time, but it could be lowered as analysis and equipment improve. Lowering the threshold increases false positives because there are 60,000 earthquakes/year with $\mathrm{m}_{\mathrm{b}}$ over 3 , as compared to $7000 /$ year with $\mathrm{m}_{\mathrm{b}}$ over 4 .

$\left(m_{b}-M_{S}\right)>1$

Explosions excite larger $P$ waves $\left(m_{b}\right)$ than surface waves $\left(M_{S}\right)$ as compared to earthquakes of the same magnitude. $M_{S}$ often cannot be measured for small explosions, thus requiring regional seismic data to discriminate between source mechanisms. Recalibrated magnitude values are being examined for events below $3.5 \mathrm{~m}_{\mathrm{b}}$. ${ }^{16}$

\section{Location}

Seventy percent of detected seismic events take place in the oceans, ruling out these events as nuclear explosions, unless there is a hydroacoustic signal with the characteristics of an explosion. Conversely, events near former nuclear test sites are examined much more thoroughly. An uncertainty in location area of $1000 \mathrm{~km}^{2}$ (18 $\mathrm{km}$ radius) can be difficult to routinely achieve for small events when recorded by limited numbers of monitoring stations. However, location errors are being reduced dramatically with the addition of more seismic stations, correlation analysis, InSAR, and 3D models. ${ }^{17}$

Depth $>10 \mathrm{~km}$

Events that are confidently located at greater than $5 \mathrm{~km}$ depth should be excluded, but this is relaxed to exclude events at depths over $10 \mathrm{~km}$.

\section{Sharing Seismic Data}

Seismic monitoring is sizable and growing. The Global Seismic Network (GSN) has 143 seismic stations (October 2007, with 134 in real-time telemetry), surpassing its goal of 128 stations, and it continues to grow. There are thousands 
of seismometers beyond the IMS and GSN networks. ${ }^{18}$ Non-IMS stations supplied excellent data on the 1998 India/Pakistan tests and the 2006 North Korean test. More seismographs enhance regional data capabilities. The Incorporated Research Institution for Seismology (IRIS) established GSN in 1986, to move beyond the obsolete, analogue Worldwide Standardized Seismograph Network. All GSN stations use digital data, which are freely available on the Internet in near-real time and from archival storage at the IRIS Data Management System (www.iris.edu). ${ }^{19}$ Broad-band GSN stations can detect very small events, such as nano-earthquakes near Hawaii with $\mathrm{m}_{\mathrm{b}}$ less than zero. Dial-up telephone access has been replaced with near-real time capabilities at $90 \%$ of the GSN sites through Internet and satellite connections. Over 50 GSN sites are now in the IMS auxiliary network, a trend that will grow. The other 80 GSN sites complement IMS coverage, giving additional, close-in regional data. Internet infrastructure has been enhanced in remote regions by GSN implementation. Operations and maintenance funding is provided by the U.S. Geological Survey for two-thirds of GSN sites. The National Science Foundation has bought equipment for many GSN sites, but increased NSF funding for hazard research after Katrina threatens funding for GSN operations and its ability to monitor central Asia.

GSN's primary purpose is basic science, which implies a long-term commitment by professional seismologists to examine data, improve seismic models, and improve sensor systems. The caliber and size of this workforce is too expensive for IMS to replicate. Regional data would be greatly enhanced if more seismic stations were involved by sharing seismic data on a near-real time basis between the IDC, the GSN, and other selected seismic stations. This would increase the number and quality of experts to correct mistakes and improve analysis, which would have prevented U.S. mischaracterization of the 1997 Kara Sea event. Data sharing with the 3000-station International Seismological Centre would be less useful because the ISC receives only volunteer phase picks and not waveform data. The ISC bulletin is produced about two years in arrears, which is too late to be useful for explosion monitoring. But, some of this very large resource could be used to assist the IDC.

\section{REGIONAL SEISMOLOGY MONITORING}

Because the surface magnitude $\mathrm{M}_{\mathrm{S}}$ is difficult to measure below magnitude 4 , it is imperative that regional seismic waves be utilized to discriminate between the possible sources of the seismic waves. Monitoring of regional waves has progressively replaced teleseismic signals as the yield threshold is now in the sub-kiloton region. Regional waves are used (1) to discriminate between seismic sources (explosions vs. earthquakes), (2) to determine the magnitude of the source, and (3) to determine the event location for attribution and on-site inspections. Regional waves predominately travel at depths less than $100 \mathrm{~km}$ 
and are strongly affected by local geology, which complicates interpretation. Regional wave amplitudes are typically larger at $1200 \mathrm{~km}$ than teleseismic amplitudes at $1800 \mathrm{~km}$. The ability to monitor at regional distances increases as additional seismic stations are deployed. When there is a region of special concern, seismographs can be located closer to the suspicious location. Regional wave magnitudes are referenced to teleseismic $m_{b}$ magnitudes to simplify discussion. Regional waves enhance the ability to detect cavity decoupling because higher frequency waves are more observable at regional distances and decoupling is smaller at higher frequencies (12 at $10 \mathrm{~Hz}$ ), compared to teleseismic waves $(70$ at $1 \mathrm{~Hz})$. The following regional waves are involved: ${ }^{20}$

- $\quad P_{n}$ are relatively small longitudinal, pressure waves that arrive first from beyond 100-200 km, mostly traveling below the crust-mantle boundary.

- $\mathrm{P}_{\mathrm{g}}$ waves arrive first if closer than 100-200 km, traveling through "granitic" crust.

- $\quad \mathrm{L}_{\mathrm{g}}$ are short period (1-6 s), large amplitude, transverse waves that arrive after $\mathrm{P}$ waves, propagating within the crust, but stopped by continental boundaries and reduced by some mountain ranges.

- $\mathrm{S}_{\mathrm{n}}$ are transverse, shear waves that arrive after $\mathrm{P}_{\mathrm{n}}$ and before $\mathrm{L}_{\mathrm{g}}$, traveling below the crust-mantle boundary.

- Coda waves are caused by backscattering from inhomogeneities in the crust and upper mantle, which appear long after the passage of body and surface waves.

The prowess of regional seismology is seen by analysis of events at the Semipalatinsk test site. Only 271 of the 340 underground nuclear tests at the Semipalatinsk test site during 1961-1989 were reasonably well-documented in the West with well-determined origin times, coordinates, and magnitudes in the open technical literature, based on teleseismic signals. However, regional data for the remaining 69 tests became available after the Cold War from seismographs located 500-1500 km from Semipalitinsk Test Site. From this data, Khalturin, Rautian, and Richards assigned magnitudes to eight tests, which had been located but whose magnitudes were unknown. ${ }^{21}$ For 31 additional tests, they estimated origin time, magnitudes, and locations for 19 of these. Of the remaining 30 poorly documented and undetected tests, 15 had announced yields less than one ton and 13 occurred simultaneously with another test, which had been detected. Thus, there were only two tests, with announced yields over one ton, for which they were unable to find seismic signals. This impressive result was obtained from older analog data, now superseded by digital broadband sensors with high dynamic range, recording in the vertical and two horizontal directions. 


\section{Event Discrimination}

$\mathrm{P}_{\mathrm{n}}, \mathrm{L}_{\mathrm{g}}$, and coda are regional waves that can be used to discriminate between possible seismic sources of an event (earthquake, chemical explosion, and nuclear explosion). ${ }^{22}$

- There is much more diagnostic information in regional, broad-band spectra than in narrowband teleseismic signals associated with magnitudes $\mathrm{m}_{\mathrm{b}}$ and $\mathrm{M}_{S} \cdot{ }^{23}$

- $P_{n}, S_{n}$, and $L_{g}$ relative spectra are very similar for earthquakes between $0.5-5 \mathrm{~Hz}^{24}$

- $P$ and $P_{n}$ relative spectra are very similar for explosions. $S_{n}$ and $L_{g}$ vary significantly from the $\mathrm{P}$ and $\mathrm{P}_{\mathrm{n}}$ curves, predominately below $2 \mathrm{~Hz}$, indicating that $S_{n}$ and $L_{g}$ are enhanced at lower frequencies for smaller/shallower explosions, more than one might expect. Deeply buried nuclear tests produce less $\mathrm{S}_{\mathrm{n}}$.

- After corrections for differential attenuation, $P_{n} / S_{n}$ ratios for explosions are very comparable between $4-6 \mathrm{~Hz}$. The high frequency $\mathrm{P}_{\mathrm{n}} / \mathrm{S}_{\mathrm{n}}$ ratio to the low frequency $\mathrm{P}_{\mathrm{n}} / \mathrm{S}_{\mathrm{n}}$ ratio is 2 for earthquakes and 5 for explosions, suggesting that $\mathrm{P} / \mathrm{S}$ ratios are a robust discriminant. Simulation modeling shows that $\mathrm{P} / \mathrm{S}$ ratios might be robust to $3 \mathrm{~m}_{\mathrm{b}}$. $\mathrm{P}_{\mathrm{n}} / \mathrm{L}_{\mathrm{g}}$ ratios give useful discrimination to $1 \mathrm{kt}$, or perhaps lower.

- Locations close to explosions have considerable high frequency content (10$100 \mathrm{~Hz}$ ) compared to rock bursts. ${ }^{25}$

- Regional coda envelopes (0.03 to $8 \mathrm{~Hz}$ ) give constant results by avoiding source and path heterogeneities that complicate interpretations of regional waves. ${ }^{26}$ Coda-derived $S_{n}$ and $L_{g}$ waveforms depend on depth of burial. ${ }^{27}$

- Small explosions within 10-20 m from inhomogeneous geologic structures convert some $\mathrm{P}$ wave amplitudes into $\mathrm{S}$ wave amplitudes at $50 \mathrm{~Hz} .{ }^{28}$ Data obtained at less than $600 \mathrm{~km}$ from former test sites are used to differentiate between explosions and earthquakes. ${ }^{29}$

- New seismic stations have not had the opportunity to monitor nuclear tests, thus extrapolations from older data must be made to accommodate analysis of new sensors.

\section{Seismic Models}

Seismic data, obtained at the surface, give information about Earth's interior, which in turn can be used to improve discrimination between earthquakes and explosions, as well as to improve location estimates. ${ }^{30}$ Models of the mantle, 
crust, and sedimentary structures are obtained from seismograms by following many ray paths between two locations. Such models are somewhat similar to $\mathrm{x}$-ray catscans, but the analogy breaks down. Geotomography is less accurate than catscans, which are based on amplitude measurements along a straightline path. Catscans are transmission measurements at one x-ray frequency without reflection, refraction, or change in wave type ( $\mathrm{P}$ to $\mathrm{S}$, etc.) that can be measured at all positions outside the body. Geotomography depends on transmission of a wide band of frequencies of many wave types that refract, reflect, and convert to another type that can not be simply disentangled by the sensor and cannot be measured at all positions.

By inverting time segments, velocity and absorption maps are obtained in 1 to 3 dimensions for different wave types within frequency bands. Velocity maps are used to calculate the passage of a given wave through the Earth, to predict the waveform at a receiving station. A conventional backward projection reverses the direction of seismic waves to locate the source position. Outlier data is removed by forward projecting waves from the calculated source location to all sensors, and then discarding data that arrives too far from the sensor that claimed to observe the event. By iterating back and forth, from seismic travel times to a velocity map and then from a velocity map to travel time and waveforms, seismic parameters are adjusted until calculated waveforms are similar to observed waveforms. Velocity and absorption vary along ray paths as a function of place, frequency, and wave type, complicating geotomography. Slow velocity regions usually have higher attenuation. Velocity and absorption parameters for the crust and upper mantle are model dependent, but modeling is extremely useful to discriminate between seismic sources and to reduce location errors, for example, from $25 \mathrm{~km}$ to $18 \mathrm{~km}$ in western Eurasia and North Africa.

\section{Location of Seismic Sources}

The location of a seismic event is usually determined by measuring the arrival times of various seismic waves at several locations. The two main causes of errors are (1) errors in travel times, and, more importantly, (2) velocity errors for seismic waves. By using a depth-dependent velocity model, travel times are converted to distances, which converge on the calculated event location. At depths greater than $200 \mathrm{~km}$, velocity is accurate to about $1 \%$, but velocity is only accurate to about $10 \%$ at shallower depths, which is relevant for regional waves in the crust and upper mantle. Seismic three-dimensional models reduce these errors because they are significantly more accurate for regional waves than the depth-only models.

A new approach uses cross-correlations between similar seismic events to reduce location errors by a factor of 10-100 over the approach based on travel times. ${ }^{31}$ For example, a regional wave traveling $500 \mathrm{~km}$ has a travel time of about 100 seconds. If there is a total 5\% error in the velocity model, this 
corresponds to a location error of $25 \mathrm{~km}$. But similar ray paths have very similar velocity profiles so that relative locations can still be precisely estimated. With the advent of broad-band digital seismographs, greater analysis examines clusters of past events between neighboring sources and sensors and between a single source and neighboring sensors. This network of paired events reduces model errors caused by an unusual structure beneath a station or beneath the source. The double-difference method links neighboring events through traveltime differences. It works best when events are separated by less than a few $\mathrm{km}$. Cross-correlations are determined with a double difference approach, by using several regional stations separated by tens of $\mathrm{km}$, and at distances up to 100-1000 km from the event. This approach was applied to regions of China and North America, giving location errors as low as $0.15 \mathrm{~km}$. Figure 3 shows a pair of similar events in China that were less than about $1 \mathrm{~km}$ apart. The applicability of this approach varies widely, to between 10 and $95 \%$ of seismic

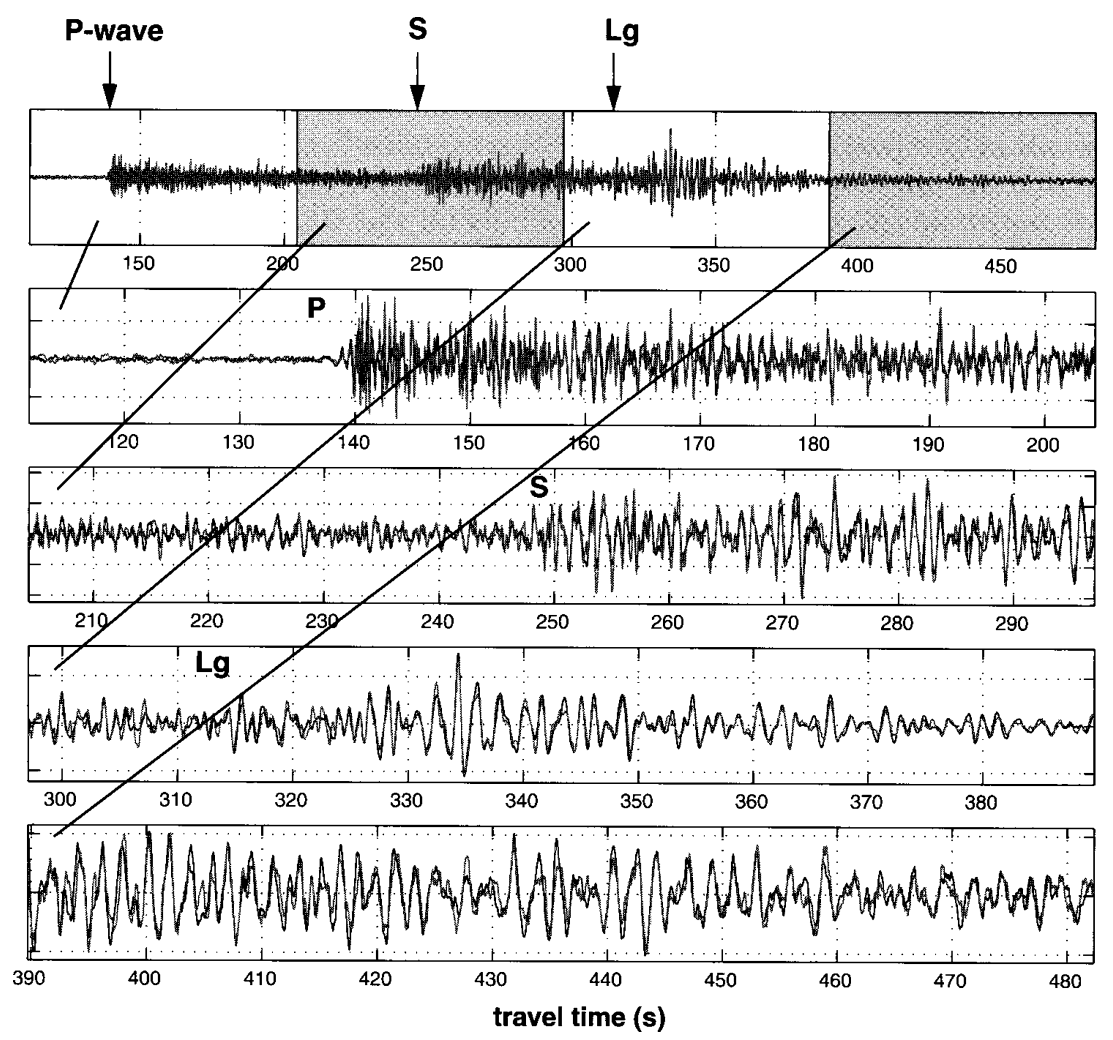

Figure 3: Chinese Earthquake Double. The waveforms of two earthquakes (in grey and black) are extremely similar over the 300-second cycle at regional distances. The cross-correlation approach determined the location of the second event to less than $1 \mathrm{~km}$ from the precursor, much superior to using travel times from phase picks (P. Richards et al., 2006). 
events, depending greatly on the region, the amount of seismic activity, and the density of seismographs. This can be applied to areas of special concern, such as Lop Nor and Novaya Zemlya. As threshold levels lower with time, more past data is applicable. The key to this approach will be the long-term commitment to individual seismic stations to increase their waveform archives.

\section{SEISMIC ARRAYS}

Since the 1960s, NORSAR has operated arrays in Norway and Spitzbergen that combine signals from individual seismographs, greatly reducing local seismic noise and lowering threshold levels by $1 \mathrm{~m}_{\mathrm{b}}$ below that of seismic networks. The resultant seismic wave is beam-formed by grouping the signals from each sensor by varying arrival times based on theoretical relative arrival times for each sensor (similar to phase-array radar). By considering the phases of the individual waves, the beam-forming approach automatically provides locations of explosions and earthquakes. Events between 2 and $2.5 \mathrm{~m}_{\mathrm{b}}$ from over $2000 \mathrm{~km}$ away are detected and identified by seismic arrays, corresponding to less than $0.01 \mathrm{kt}$ for tamped yields and to less than $1 \mathrm{kt}$ for explosions in large cavities.

\section{Waveform Correlation}

Problematic seismic signals were observed by Spitzbergen Array (1280 km distant) and NORSAR array $(2320 \mathrm{~km})$ from near Novaya Zemlya Test Site on August 16, 1997. ${ }^{32}$ The main event of $3.5 \mathrm{~m}_{\mathrm{b}}$ was followed four hours later by a small aftershock of $2.5 \mathrm{~m}_{\mathrm{b}}$. The two waveforms were strongly correlated in timing and shape, indicating that the two events took place at the same location with the same source mechanism. The similarities showed that the second event was an aftershock to the first signal, which was an earthquake in the Kara Sea and not a nuclear test. (See the discussion on Three Recent Nuclear-Test Events for more details.) In another experiment the NORSAR group used the template waveform from a $3.5 \mathrm{~m}_{\mathrm{b}}$ earthquake to detect and identify events as low as $0.5 \mathrm{~m}_{\mathrm{b}}$ at $600 \mathrm{~km}$ distance. The false alarm rate at large-aperture arrays is much less than at small-aperture arrays. The correlation approach is very powerful for studying events at nuclear test sites, and it now being extended to earthquakes and chemical explosions.

\section{Correlation Detection}

This approach was used to study 11 chemical explosions in cavities of 200 to $1000 \mathrm{~m}^{3}$ at Alvdalen, Sweden, $142 \mathrm{~km}$ from the NORESS array. ${ }^{33}$ Seismic waveforms were compared with a known event over a narrow frequency band of 14-18 Hz with optimal signal-to-noise. All five 1-ton chemical explosions were automatically detected by NORESS and NORSAR arrays during the course of a 
year, with a very low false alarm rate. The Spitzbergen array was able to detect rock bursts $50 \mathrm{~km}$ away. Correlation detection is limited to comparing signals coming from a footprint of 1-2 wavelengths, some $10 \mathrm{~km}$ at $1 \mathrm{~Hz}$. Correlation events must exhibit little variation in source mechanism and time history. Correlation detection can rule-out mining explosions and rule-in nuclear explosions at a given location. A very small signal to noise ratio is used for these detections. Assuming a false alarm probability of $10^{-6}$, Frode Ringdal and his NORSAR co-workers calculated the signal-to-noise ratio in decibels (with respect to $0 \mathrm{~dB}$ at SNR = 1) needed to obtain $90 \%$ detection probability: They obtain $7 \mathrm{~dB}$ for a single sensor ( $\mathrm{SNR}=5),-3 \mathrm{db}$ for a 9-element array ( $\mathrm{SNR}=0.5)$, and from $-15 \mathrm{~dB}$ to $-20 \mathrm{~dB}$ for more complex configurations (SNR 0.03 to 0.01 ). When prior data exists, cross-correlation between waveforms are 10 to 100 times more accurate in determining locations than traditional timing methods. NORSAR gave these conclusions:

We present evidence that correlators can be used to lower detection thresholds by 0.5 to 1 magnitude units over standard energy detection algorithms. Thus they offer roughly the same enhancement in detection performance that is achieved by replacing single sensors with arrays. This enhancement can be achieved in addition to the sensitivity increase afforded by arrays. The fact that correlators are specific to individual sources makes them attractive as event classifiers. This feature can be exploited to construct efficient screens for mining explosions or earthquake aftershocks.

\section{INFRASOUND, HYDROACOUSTIC, AND RADIONUCLIDE MONITORING}

\section{Infrasound}

Infrasound $(0.01-10 \mathrm{~Hz})$ has a marginal ability to detect small underground nuclear tests, but it can discriminate between atmospheric nuclear explosions and chemical explosions and earthquakes. ${ }^{34}$ Combining pressures at the node of an axial array of tubes reduces incoherent noise fluctuations, although coherent infrasound remains. Spatial triangulation is used to determine locations of atmospheric events, which can be superior to seismic locations if little energy is transmitted into the ground. IMS infrasound monitoring uses a sparse network with a $2500-\mathrm{km}$ spacing. Large and small apertures are used to measure low frequencies $(0.03$ to $0.1 \mathrm{~Hz})$ and frequencies over $1 \mathrm{~Hz}$. Time and frequency-based cross-correlations are used to obtain characteristics of the signal to discriminate between source mechanisms. Wind speed exacerbates wind noise, which rises by $20 \mathrm{~dB}$ if wind speed is raised from $1 \mathrm{~m} / \mathrm{s}$ to $5 \mathrm{~m} / \mathrm{s}$. For underground events, the seismic network has much greater location accuracy than infrasound, but less than that of interferometric synthetic aperture radar on satellites if they 
observe the location of the test. The United States can detect atmospheric tests with bhangmeters in space, but the other nations that participated in CTBT negotiations selected infrasound sensors for the IMS because they did not have bhangmeters. The NAS panel concluded that the infrasound "two-station detection thresholds are below $1 \mathrm{kt}$ worldwide and below $0.5 \mathrm{kt}$ on continents in the northern hemisphere." NORSAR showed that there is a high correlation between seismic signals and infrasound signals from mining explosions. ${ }^{35}$ Detection of 0.019-kt chemical explosions have been observed at $2000 \mathrm{~km}$, but detection capability can be significantly reduced when the monitoring station is located upwind from the source or normal to the stratospheric wind direction. ${ }^{36}$

The acoustic pressure at a node of tubes is governed by the speed of sound, which gives a frequency-dependent response. Two new approaches take advantage of the fact that the speed of light gives a response that does not depend on frequency.

\section{Piezoelectric Sensors}

An array of 90 piezoelectric sensors is attached to tube walls of a three-arm infrasound detector. ${ }^{37}$ The digitized signals are combined and correlated with much greater sophistication and corrections than pressure addition at the node of an axial array. Noise power is reduced as the inverse of the number of sensors when the signals are averaged and not correlated, but multiple correlated sensors reduce wind noise by more than the $1 / \mathrm{n}$.

\section{Optic Fiber Infrasound Sensor (OFIS)}

An optical fiber is split into two fibers, which are wound separately around a pliable tube, permitting the optical path to stretch as pressure deforms the tube. The change in path length is measured by interferometry with a laser pulse that is split into the two fibers and combined at the other end prior to a photodetector. Integrated pressure is measured by combining the wave and its derivative, forming an ellipse. ${ }^{38}$ Preliminary experiments suggest that wind noise is reduced by $20 \mathrm{~dB}$ in low-wind conditions of $1 \mathrm{~m} / \mathrm{s}$ wind between $1-10$ $\mathrm{Hz}$. Temperature differences must be minimized to obtain good data, similar to traditional tube arrays. Optical polarization in the two fibers should be similar, and not at right angles. A multiple-arm OFIS array has the potential to improve signal detection, source discrimination, and velocity direction.

\section{Hydroacoustic Monitoring}

Propagation of ocean acoustic waves has low dispersion and small loss rates when in the oceanic channel. Hydroacoustic sensors are used to discriminate between oceanic earthquakes and explosions (more power at 5-100 Hz). If an 
oceanic event lacks a robust explosive hydroacoustic signal, the event is surely an earthquake. ${ }^{39}$ Event locations deduced from hydroacoustic data are moderately accurate ( $30 \mathrm{~km}$ at $1000 \mathrm{~km}$ with a horizontal array), but they complement more accurate locations obtained from seismology. The NAS panel concluded that hydroacoustic monitoring has a "yield threshold [of] just a few kilograms for most oceans in the Southern Hemisphere. Almost all the world's ocean basins will be monitored down to better than one ton." ${ }^{40}$ The IMS network of six hydrophone arrays and the five (less-capable) T-Phase ${ }^{41}$ stations will have a greater sensitivity in the Southern Hemisphere, whereas the seismic network is most sensitive in the Northern Hemisphere. The IDC developed the Hydroacoustic Azimuth and Slowness Estimator to discriminate source mechanisms and determine azimuthal location to within 1 degree with few false positives, keying to the bubble pulse signature of an explosion.

Coupling explosive energy into the oceanic waveguide is very efficient in deep oceans, but shallow oceans can block acoustic energy from reaching the oceanic waveguide. The 2004 Sumatra earthquake gave a much larger signal on the southern side of Diego Garcia as compared to its northern side (32 decibel reduction at $20 \mathrm{~Hz}){ }^{42}$ In response to the tragic death of 300,000 , the IMS network reduced its tsunami warning time from 2 hours to 20 minutes and has made its data available on a confidential basis. Hydroacoustic blockage models determine travel times to within $0.1-5 \%$, using underwater geography, temperature, salinity, and surface roughness. ${ }^{43}$ Databases and experiments are being used to enhance these tools.

\section{Radionuclide Monitoring}

Detection of fission radionuclides gives definitive identification that an event was a nuclear explosion, as was the case of the 2006 North Korean test (see Three Recent Nuclear-Test Events). Two days after the 0.6-kt test, 300 radioactive xenon nuclei were detected, confirming that it was a nuclear test. The IMS station in the Northwest Territories of Canada contributed to this analysis. Information collected from radionuclide samplers takes days or weeks to collect and analyze. Soviet underground nuclear tests at Novaya Zemlya vented 90\% of the events between 1964 and 1988 and the United States also had venting problems for decades. Noble gas radionuclides (especially Xe) are particularly difficult to confine. The IMS radionuclide network is planned to provide detection if as little as 10 percent of radioactive noble gasses generated by a 1-kt underground explosion are vented. Because of advances described later, the NAS panel concluded that in many places this threshold is reduced by an order of magnitude. "Present estimates place a threshold limit of 0.1 to 1.0 kilotons for a nuclear explosion on the continents and a threshold limit of 1 to 2 kilotons on the oceans." ${ }^{\prime 4}$ The panel further concluded that detection probability will exceed 90 percent across most of Europe and Asia and over 50 percent over most 
of the southern oceans. Locating a source is not precise because it depends on models using wind and weather data.

Forty of 80 IMS radionuclide stations will monitor radioxenon isotopes. Prototype radioxenon detectors were built by France, Russia, and Sweden and the U.S. Pacific Northwest National Laboratory (PNNL) developed the Automated Radioxenon Sampler/Analyzer (ARSA), which detects low-levels of four radioxenon isotopes. ARSA (1) collects air at very high rates, (2) uses high-efficiency gamma and beta coincident detectors, (3) minimizes background counts, (4) minimizes radon in separated xenon samples, (5) conducts short cycles of continuous separations with prompt subsequent analysis of the gas samples, and (6) functions without an operator and without significant maintenance. ${ }^{45}$ The ARSA system reduces $40 \mathrm{~m}^{3}$ of air in 8 hours to about 10 $\mathrm{cm}^{3}$ of gas that is $50 \%$ xenon and $50 \%$ nitrogen. This tour de force involves sophisticated xenon trapping, xenon purification, xenon quantification, and radioxenon measuring. The minimum detection concentration of $\mathrm{Xe}-133$ is 0.1 $\mathrm{mBq} / \mathrm{m}^{3}\left(0.4\right.$ counts $/ \mathrm{m}^{3}$-hour) and Xe-135 is $0.5 \mathrm{mBq} / \mathrm{m}^{3}$, which is an order of magnitude less than the $1 \mathrm{mBq} / \mathrm{m}^{3}$ goal (24-hour sampling). ARSA measurements show that ambient levels of Xe-133 can vary significantly near nuclear reactors from normal values of 0.7 to $1.5 \mathrm{mBq} / \mathrm{m}^{3}$ to over $20 \mathrm{mBq} / \mathrm{m}^{3}$.

The IMS deploys both manual and automatic radionuclide systems. For example, PNNL also developed the Radionuclide Aerosol Sampler/Analyzer (RASA), which is sensitive down to 1 million radioactive nuclei attached to aerosols or dust. This is $10^{-17}$ of the $10^{23}$ radionuclides produced from a $1-\mathrm{kt}$ test. According to PNNL, a single RASA would eventually detect an atmospheric explosion anywhere in the same hemisphere. A possible new sensor is being researched that separates aerosols on the basis of their size. ${ }^{46}$ This takes advantage of the fact that aerosols from atmospheric explosions have diameters less than $0.1 \mu \mathrm{m}$, and aerosols from underground explosions have diameters larger than $1 \mu \mathrm{m}$, whereas aerosols with natural radioactivity have diameters between 0.1 and $1 \mu \mathrm{m}$. In addition, traditional radioactive sampling during on-site inspections can determine if a nuclear test took place. ${ }^{47}$

\section{SPACE-BASED, INTERFEROMETRIC SYNTHETIC APERTURE RADAR}

Classified, space-based systems monitor optical, infrared, radar, nuclearparticle, electromagnetic pulse, and communications signals. This article will discuss only the relatively new, interferometric synthetic aperture radar (InSAR). InSAR nicely complements IMS capabilities for the case of 1-kt tests at depths down to at least 500 meters. InSAR results are not nearly as timely as seismology, but the discrimination and location measurements can, in some cases, surpass that of seismology. Synthetic aperture radar (SAR) produces detailed images of surfaces, even when there is dense cloud cover. SAR satellites 
transmit radar pulses and receive the reflections as the satellite moves along its flight path, synthesizing a large-aperture antenna. Signals reflected from the forward velocity direction have a positive Doppler shift, while signals received from the aft direction have a negative Doppler shift, creating a one-dimensional map. The second dimension comes from timing analysis. Longer collection and computer times increase the effective antenna size, which improves spatial resolution of SAR images. By combining SAR images taken at two different times at very similar orbital locations, InSAR images measure changes in topography (deformation) accurate to $0.2-0.5$ centimeters. InSAR images of subsidence after underground tests at the Nevada and Lop Nor test sites have been obtained by Paul Vincent et al., using data from European Space Agency ERS and Envisat satellites, as well as Canadian and Japanese satellites. ${ }^{48}$ SAR and InSAR can also discover site preparation and other evidence of nuclear testing. InSAR has been used to study subsidence above tunnels, land-use management, soil moisture, water pumping and river runoff (volume and sediment), sea surface heights, glacier thickness and dynamics, and real-time measurements of seismological events. InSAR is now a widely adopted technology, available to all CTBT States Parties at reasonable prices from commercial vendors. Canadian Radarsat SAR data ( $8 \mathrm{~m}$ horizontal resolution, $50 \mathrm{~km} \times 50 \mathrm{~km}$ ) costs $\$ 3000$, plus $\$ 1000$ for a rush acquisition (29-60 hours in advance) and $\$ 1000$ for near-real time acquisition (2-6 hours after reception). ${ }^{49}$ Sophisticated InSAR software costs $\$ 20-40,000$. At some point there will be SAR data with 1-m horizontal resolution available from commercial sources, which will enhance InSAR resolution. The United States has four Lacrosse SAR satellites, each visiting most ground sites twice a day. Data obtained from National Technical Means and cooperative measures (see Cooperative Monitoring at Test Sites) may be used by the CTBT Executive Council if obtained in accordance with international law to request an on-site inspection (Article IV.D.37).

Reflected radar has two kinds of information, amplitude and phase, which InSAR combines at each pixel from data taken before and after an underground nuclear test. The result is an interference pattern map. Topography plus subsidence are obtained in the second SAR viewing, but the interferometric image, when acquired from two nearly identical viewing locations, measures subsidence after removal of topography. ${ }^{50}$ When the satellite returns to the same location above the Earth, the phase image should be the same if nothing has changed. If this is not true, then something happened, such as subsidence. The double-difference method uses three SAR images of the same scene. The interferogram obtained from the first two SAR images is subtracted from the interferogram from the last two SAR images, to obtain a double-difference interferogram. By using several interferograms from different time spans, background contributions to subsidence from atmospheric and vegetation scattering can be minimized. Another approach, used by Vincent, obtains an interferogram from two SAR images, and then subtracts the digital elevation model (DEM) map, 
to obtain subsidence. These approaches measure subsidence with an accuracy of $0.2 \mathrm{~cm}$ (Nevada Test Site and Jubilee subway) and $0.5 \mathrm{~cm}$ in other locations. This approach is successful even when a visible crater is not formed. InSAR can discriminate between earthquakes (asymmetrical pattern) and explosions (circular pattern). InSAR data has a horizontal resolution of 30 meters, which is much smaller than typical crater diameters of 100 meters. InSAR has improved location estimates for earthquakes by $20 \mathrm{~km}$ in some cases. The subsidence diameter of about $1 \mathrm{~km}$ gives an area that is 100 times larger than visible craters. A typical radar frame covers 10,0000 square kilometers, sufficient to search wide areas. InSAR can direct on-site inspections to better than $0.1 \mathrm{~km}$ to search for radioactivity and other testing evidence, a much more accurate footprint than the $1000 \mathrm{~km}^{2}$ allowed by CTBT to locate on-site inspections. Dynamic InSAR measurements can directly observe seismic waves during an event from airborne platforms, but this approach is too costly for CTBT monitoring.

There are some three-dozen triple-axis seismometers located on or near the Nevada Test Site. The data for the three nuclear events in Figure 4 have local magnitudes and depth of burial as follows: Galena (3.91 $\mathrm{M}_{\mathrm{L}}, 401$ meters), Divider $\left(4.39 \mathrm{M}_{\mathrm{L}}, 340 \mathrm{~m}\right)$, and Victoria $\left(2.65 \mathrm{M}_{\mathrm{L}}, 244 \mathrm{~m}\right)$. These local magnitudes can be interpreted with the aid of the Nonproliferation Experiment (NPE), an
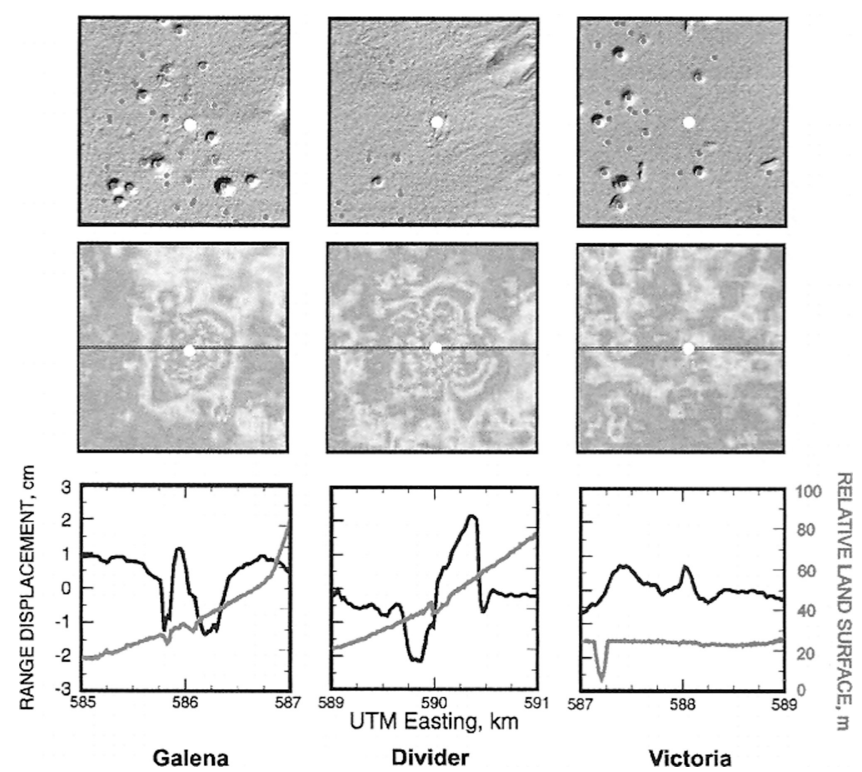

Figure 4: Subsidence After Three 1992 Nuclear Tests at NTS. (Top) Digital elevation map with 10-m resolution locates sites of underground tests (dots). (Center) Interference pattern displays a cycle of $2.8-\mathrm{cm}$ vertical displacement, showing subsidence during the time interval between two SAR pictures. (Bottom) Profile plots of near-vertical displacement (left scale) and surface topography (right scale). Galena (Left, 3.9 $\mathrm{M}_{\mathrm{L}}$ ) and Divider (Middle, 4.4 $M_{L}$ ) show readily observable subsidence, whereas Victoria (Right, $2.7 M_{L}$ ) was not observable (P. Vincent, 2003). 
explosion of $1.4 \mathrm{kt}$ of ammonium nitrate fuel oil (September 22, 1993, 4.06 $\mathrm{M}_{\mathrm{L}}$, $405 \mathrm{~m}$ ). Jack Murphy concluded that chemical explosions couple twice as effectively to seismic signals as tamped nuclear explosions with similar frequency components, giving a nuclear effective yield of $2.8 \mathrm{kt} .{ }^{51}$ Using the NAS conversion for magnitude to yield, the readily observable Galena and Divider had yields of $2 \mathrm{kt}$ and $6 \mathrm{kt}$, respectively, whereas the non-observable Victoria had a yield of $0.1 \mathrm{kt}$. Because Galena was very observable (Figure 4), InSAR can identify and locate nuclear tests of less than $1 \mathrm{kt}$ at depths of 400 meters with a location accuracy of 100 meters if prior-test SAR data are available. This clearly strengthens CTBT monitoring.

Long-term subsidence continues as underground damage relaxes with settlement and closure of chimney voids, gravitational settlement of large detached
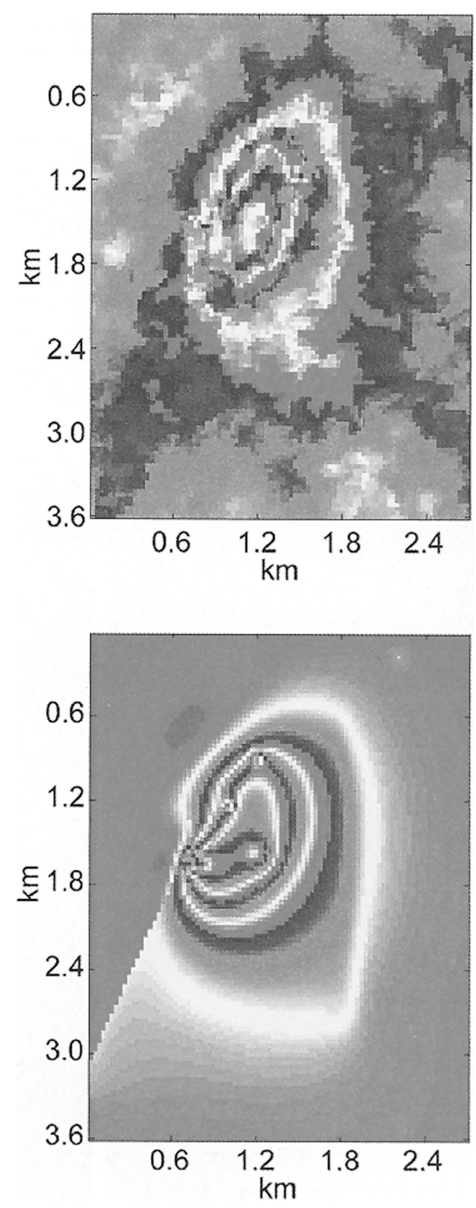

Figure 5: Theory vs. InSAR Data. InSAR data from the Nevada Test Site (top) is compared to calculations with elastic, finite-element models (bottom) that take into account local geology. One color cycle is $2.8 \mathrm{~cm}$ (P. Vincent, 2003). 
zones, or slips on nearby faults (Figure 5). Vincent used InSAR to determine subsidence relaxation rates in mm/year for 11 nuclear tests over $20 \mathrm{kt}$ that took place during 1989-92. These larger tests were at an average depth of 613 $\mathrm{m}$, producing local magnitudes between 5.03 and 5.75 (average of 5.4). Vincent showed that nuclear tests can be located when no SAR data existed prior to a test, allowing the characterization of 12 additional explosions. The initial subsidence rates of 17 tests varied greatly between 0.43 and $6.95 \mathrm{~cm} / \mathrm{yr}$, caused by differing geology, explosion environments (tunnels and shafts), and time histories. The subsidence rate slows over time, with an exponential decay constant of about 0.01-0.06 per year, whereas test cavity over-pressure dropped from 42 atmospheres to 37 atmospheres during 1992-99. The threshold to detect and identify tests without prior SAR data is over $20 \mathrm{kt}$, which is of marginal interest for CTBT monitoring because seismology is extremely robust at that level. However, the 100-m location accuracy from InSAR is relevant.

\section{InSAR Limitations}

Unclassified SAR data can be obtained from foreign satellites, although the United States InSAR Working Group is planning an unclassified SAR satellite. InSAR sensitivity depends on test yield, test depth, site geometry (horizontal or vertical), and the ability of the local geological structure to support the cavity roof. InSAR measures subsidence to an accuracy of $0.2-0.5 \mathrm{~cm}$ with a threshold yield of less than $1 \mathrm{kt}$ at depths of at least 400 meters when prior SAR data exists, and to about $20 \mathrm{kt}$ when no prior SAR data exists. Previously undetected subsidence above London's Jubilee Tunnel was observed to be linear with time with an accuracy of $0.2 \mathrm{~cm}$ from the scatter of individual measurements (Figure 6). ${ }^{52}$ Relative subsidence is determined with respect to fixed heights of neighboring buildings or geological structures. The main source of error is caused by scattering fluctuations from water vapor (not clouds), which is reduced by averaging over several data runs. Tree motion and vegetation and ice changes also contribute to errors.

\section{COOPERATIVE MONITORING AT TEST SITES}

\section{Monitoring Near Experiments}

Inspector and inspected nations could cooperatively monitor (1) for small tests near a test site and (2) for sub-critical experiments at very close distances without compromising secrecy. The data could be released if both nations agree to do so. Sub-kiloton tests have a lesser military significance, but cooperative, close-in monitoring greatly lowers monitoring thresholds, reducing suspicions. Cooperative measures can determine if an experiment is hydronuclear, which is a CTBT violation, or hydrodynamic, which is permitted. ${ }^{53}$ CTBT negotiations 


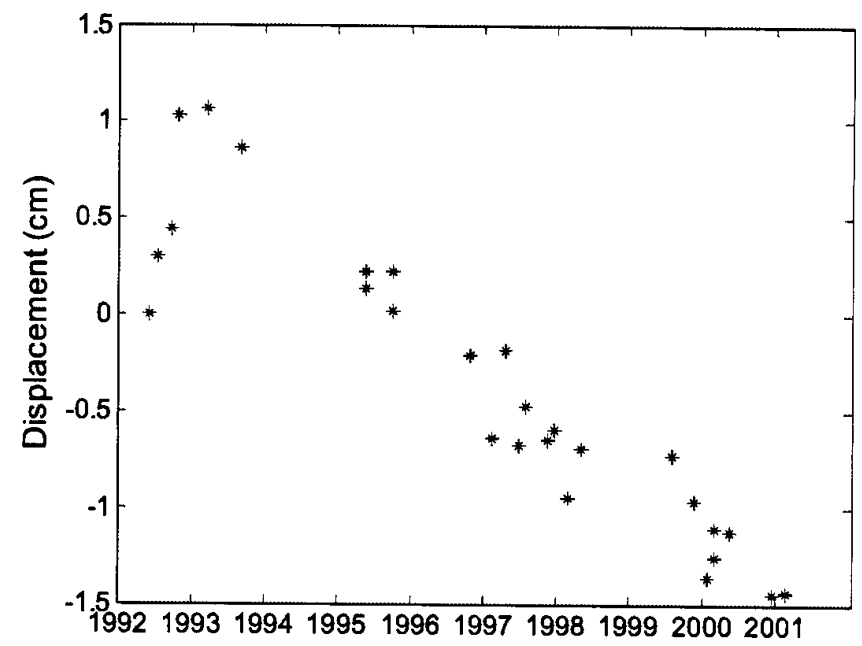

Figure 6: Jubilee-Line Subsidence. Site elevation above London's Jubilee Line tunnel from InSAR reveals subsidence, which is linear with time $(2 \mathrm{~cm}$ between 1993 and 2001 above the $20-\mathrm{m}$ deep tunnel). Accuracy is better than $0.2 \mathrm{~cm}$ for a single measurement ( $G$. Rennie, 2005).

defined hydronuclear tests as those having a nuclear yield of less than 4 pounds (1800 grams) TNT equivalent, whereas hydrodynamic tests do not reach nuclear criticality. Jones and von Hippel calculated integrated radiation doses at 2 meters distance for a variety of nuclear experiments, giving monitoring thresholds between $\mu$ gram- and gram-equivalent. ${ }^{54}$ They concluded that cooperative monitoring "should be adequate to verify that nuclear yields greater than grams of TNT equivalent had not occurred, even allowing for the possibility of substantial shielding."

\section{Hydrodynamic--Hydronuclear Threshold}

A test can be considered to be a legal hydrodynamic test if the neutron fluence from fission is less than the naturally occurring spontaneous neutron fluence. Four kg of weapons grade plutonium (6 percent plutonium-240) release $2.2 \times 10^{5}$ spontaneous neutrons per second. This gives a neutron flux at $2 \mathrm{~m}$ of $0.2 / \mathrm{cm}^{2}$-sec, when 50 percent of neutrons escape the device. A weekly read detector at $2 \mathrm{~m}$ receives $1.3 \times 10^{5} / \mathrm{cm}^{2}$, corresponding to $0.4 \mathrm{mg}$-equivalent. If the experiment doubles the normal dosimeter dose, fission yield of $0.4 \mathrm{mg}$ must have taken place. Active interrogation can complicate matters. A berylliumamericium-241 on-off source produces $10^{8}$ neutrons per pulse, which gives a neutron fluence of $100-1000 / \mathrm{cm}^{2}$, which could give a false positive. Pulsed neutron generators $\left(10^{11}\right)$ and fast critical assemblies $\left(10^{17}\right)$ would further complicate matters. These results show that passive dosimetry is accurate, less misleading, and less political. The JASON panel estimated a monitoring limit of 1-milligram equivalent ( 1 nanoton) could be obtained with passive dosimeters. ${ }^{55}$ 
The JASONS concluded that active measurements using an external neutron source were not useful to determine if criticality took place since the source "would seriously interfere with other diagnostics, and could possibly produce a false positive measurement."

\section{Monitoring Next to a Test Site}

The Intelligence Community wants enhanced capabilities to learn more about other countries, whereas the Defense Department wants less-capable measures to protect DoD secrets. The ultimate choice is a political compromise. A credible regime to monitor nuclear experiments within a $\mathrm{km}$ of the test site is described in what follows.

\section{Passive Seismic for Small Nuclear Tests}

The number of aftershocks following a nuclear test varies slightly with yield between 1 and $10 \mathrm{kt} .{ }^{56}$ Local seismographs placed within a few $\mathrm{km}$ of a nuclear explosion detect over 50 small aftershocks between magnitudes 1 and -2 after an explosion between magnitudes 4 and 5 . Seismic detectors should be located in a quiet place, away from noisy machinery. Several seismometers at different locations can locate the seismic source. The United States routinely measured low magnitude aftershocks after nuclear tests down to $-3 m_{b}$ near the Nevada Test Site. ${ }^{57}$ This level corresponds to a passive seismic threshold of less than $10 \mathrm{~kg}\left(10^{-5} \mathrm{kt}\right)$. It is useful to calibrate the test site with a few small chemical explosions, to better understand local seismic signals. Two technicians can install commercial systems in several days, which are relatively easy to operate. False positives from chemical explosions, rockbursts and rockfalls, and human activity can be ruled out with infrasound microphones.

\section{Radioxenon Detection}

Both the United States and the former Soviet Union have had considerable difficulty in preventing accidental releases of radioactive isotopes from nuclear tests. Noble gases (xenon-135, xenon-133, and argon-37) are particularly difficult to constrain, giving a strong indication that a nuclear test took place (see Radionuclide Monitoring). The Automatic Radioxenon Sampler Analyzer (ARSA) lowered the threshold detection level by a factor of ten for radioxenon to $0.1 \mathrm{mBq} / \mathrm{m}^{3}$ (0.4 counts $/ \mathrm{m}^{3}$-hour). The Radionuclide Aerosol Sampler/Analyzer (RASA), deployed at IMS sites, has a threshold detection level of $0.01 \mathrm{mBq} / \mathrm{m}^{3}$.

\section{Unattended Video Monitoring}

Data obtained in near-real time can be stored and retrieved with telecommunications. Solid-state technology needs little maintenance. 


\section{EMP Detection}

Criticality experiments emit an easily measurable electromagnetic pulse (EMP) near the experiment. EMP from an underground nuclear test is highly absorbed by the ground. However, lower frequency components, which diminish as the fourth power of the distance, are observed if induction coils and antennae are located within 100 meters of a 0.1-kt test. Lightning gives an EMP, but this false signal can be negated with cooperative tests and by rejection circuitry for steady-state deployment. The frequency region below $10 \mathrm{kHz}$ does not reveal weapons design information, but higher frequencies should be avoided because that region can reveal weapon design information. EMP measurements can play a unique role because a nuclear explosion gives a larger EMP signal than a chemical explosion of the same yield.

\section{THREE RECENT NUCLEAR-TEST EVENTS}

\section{Kara Sea Non-Event}

A small seismic event took place near the northern Novaya Zemlya (NZ) Test Site on August 16, 1997. Within days, nongovernmental seismologists located the event $100 \mathrm{~km}$ from NZ in the Kara Sea at $400 \mathrm{~m}$ depth (Figure 7). ${ }^{58}$ This location meant that the event was not a nuclear explosion, but an earthquake. However, two weeks later the Departments of State and Defense labeled the event as having "explosive characteristics" and a month after the event, U.S. agencies still characterized the event as "unresolved" or "lending itself to alternative interpretations." This was an error by U.S. agencies and not by CTBTO. The Kara Sea seismic data from Northern Finland is shown in Figure 8, along with spectrum from a Soviet nuclear test at the northern NZTS. This data shows

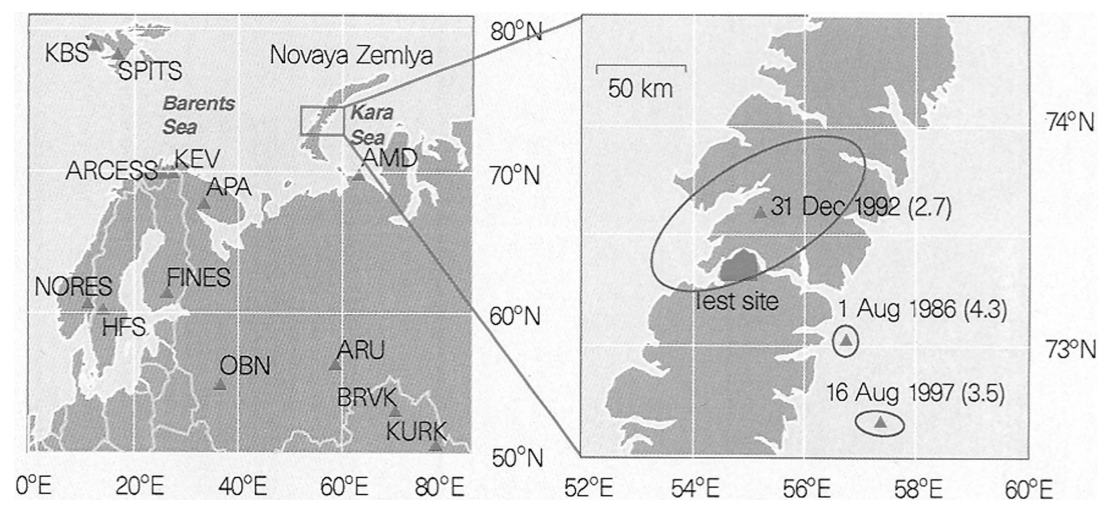

Figure 7: Location Accuracy of the Kara Sea Event. Locations of the NZTS and earthquakes (with magnitudes during 1986-1997) are shown with error ellipses for high confidence (90\%). NORSAR later showed the event of August 16, 1997 was located to within $1 \mathrm{~km}$ of its small aftershock (P. Richards and W.Y. Kim, 1997). 

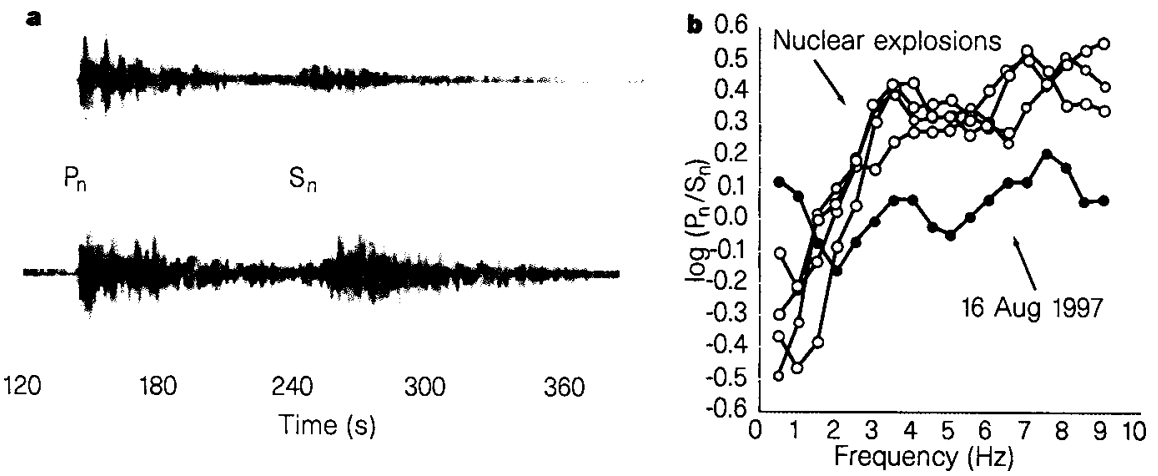

Figure 8: Kara Sea Event vs. Nuclear Test Data. (left top) Soviet nuclear test of 24 October 1990, detected at KEV seismic station in Northern Finland, 1048 km from the northern NZTS, and (left bottom) the Kara Sea event at a distance of $1127 \mathrm{~km}$. The Kara Sea event had a much smaller $\mathrm{P} / \mathrm{S}$ ratio between 3-9 Hz as compared to that of nuclear explosions ( $\mathrm{P}$. Richards and W.Y. Kim, 1997).

that the Kara Sea event was an earthquake because the $\mathrm{P} / \mathrm{S}$ ratio at higher frequencies $(2-9 \mathrm{~Hz})$ is much lower than for nuclear explosions. Furthermore, the time delay between $\mathrm{P}$ and $\mathrm{S}$ waves is 8 seconds longer for the Kara Sea event, as compared to nuclear explosions at NZ, which implies that the event could not have been at the test site. Further confirmation came from the small aftershock $\left(m_{b}=2.5\right)$, four hours after the Kara Sea event $\left(m_{b}=3.5\right)$, detected by NORSAR (2320 km away) and Spitsbergen (1300 km away) arrays. Waveform correlation analysis showed that the source mechanism for the two events was the same for both events and it showed the two event locations were closer than $1 \mathrm{~km} .{ }^{59}$ There were six independent methods showing that the event was an earthquake and not a nuclear test: (1) P/S ratio, (2) amplitude at high frequency (3-9 Hz), (3) location, (4) S-P time difference, (5) similarity of aftershock data, and (6) waveform similarity to a 1986 earthquake at the same location. The Kara Sea event showed that array monitoring is robust to less than $2.5 \mathrm{~m}_{\mathrm{b}}$ $(0.01 \mathrm{kt})$ in the vicinity of Novaya Zemlya.

\section{Indian and Pakistani 1998 Tests}

The Indian and Pakistani nuclear tests of May 11, 28, and 30 were automatically detected and located by the Prototype IDC within 1 hour, without being screened out by the IDC automatic process. Seismic data were detected by 62 stations, used by the prototype IDC, including the regional station at Nilore, Pakistan. ${ }^{60}$ Eight regional stations in the completed IMS network would be expected to detect events of this type with a capability down to $2.5 \mathrm{~m}_{\mathrm{b}}$. The test sites for the May 11 and May 28 events were readily located with commercial satellite images with 5-meter resolution by comparing pre- and post-images. The May 11 seismic signal had a signal-to-noise ratio greater than 1000 at 
Nilore. The yields of the multiple tests (perhaps $1 \mathrm{~km}$ apart) were one-fourth of what was claimed by India and Pakistan, lowering the May 11 Indian yield estimate from $55 \mathrm{kt}$ to $12 \mathrm{kt}$ (9-16 kt, 95\% confidence, $\mathrm{m}_{\mathrm{b}} 5.0$ ), the May 13 Indian event $\left(<\mathrm{m}_{\mathrm{b}} 2.5\right.$ ) from $0.8 \mathrm{kt}$ to $0.03 \mathrm{kt},{ }^{61}$ the May 28 Pakistani event from 30-35 kt to $9 \mathrm{kt}\left(6-13 \mathrm{kt}, \mathrm{m}_{\mathrm{b}} 4.9\right)$, and the May 30 event from no-claim to $4 \mathrm{kt}\left(2-8 \mathrm{kt}, \mathrm{m}_{\mathrm{b}} 4.3\right)$. The lower yield estimates diminish the Indian claim of a significant hydrogen weapon.

\section{North Korean Test of October 9, 2006}

The 0.6-kt, North-Korean test was promptly detected and identified at seismic stations in Australia, Europe, North America, and Asia. ${ }^{62}$ Over 20 IMS seismic stations detected the blast. The U.S. Geological Survey took five hours to obtain a good estimate of the test location. Figure 9 displays the spectra for two magnitude 4 events, the October explosion at a distance of $373 \mathrm{~km}$ and an earthquake at $342 \mathrm{~km}$. The October signal was identified as an explosion because of the large $\mathrm{P}$ wave (pressure wave) amplitude and weak $\mathrm{S}$ wave (shear wave) amplitude, compared to the small $\mathrm{P}$ wave amplitude for the earthquake. The regional seismic data was obtained by a non-IMS, Chinese-U.S. operated station in Mudanjiang, China, showing that CTBT monitoring is improved with

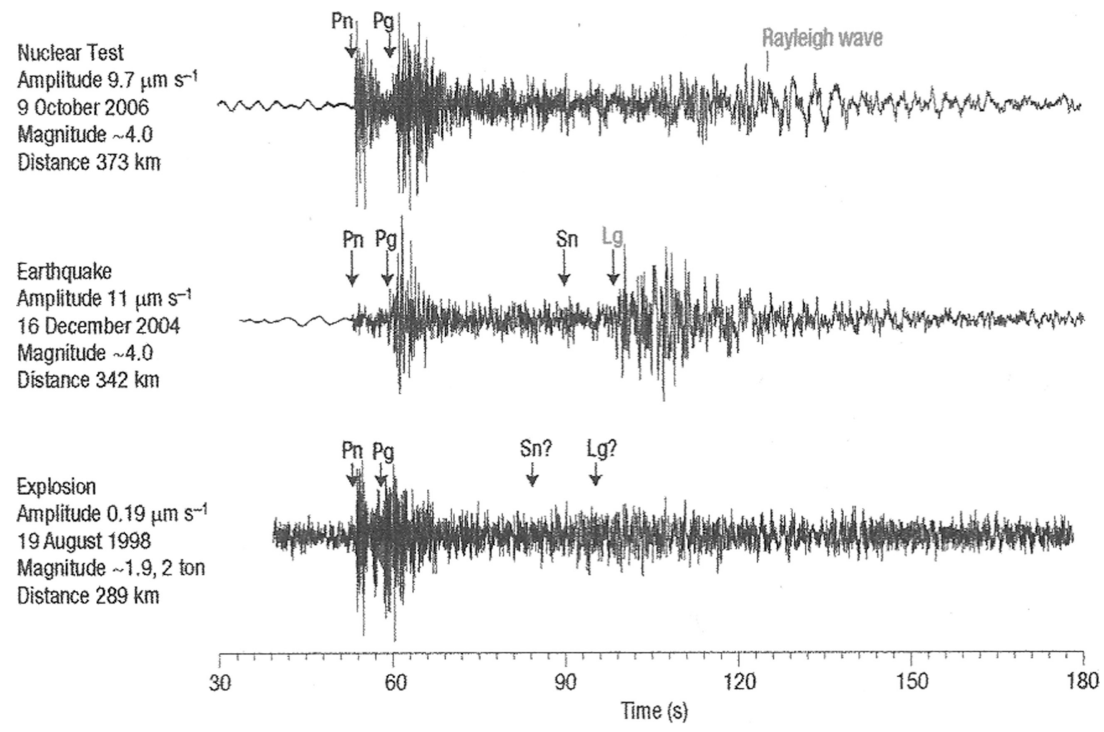

Figure 9: North Korean 2006 Test, Earthquake, and Chemical Explosion. Seismograms with vertical ground velocity in micrometers per second recorded at Mudanjiang, China. (top) North Korean test (October 9, 2006, magnitude 4, distance of $373 \mathrm{~km}, 0.7 \mathrm{kt}$ ), (middle) earthquake (December 16, 2004, magnitude 4, $342 \mathrm{~km}$ ), (bottom) small underground chemical explosion (August 19, 1998, magnitude 1.9, 289 km, 0.002 kt). The strong P-wave amplitude in the October 9, 2006 trace shows the event was an underground explosion. The waveform for the small chemical explosion has the same structure as the data from the underground nuclear test (P. Richards and W. Y. Kim, 2007). 
nearby stations. Because this was a first test, it was not surprising that radioactive xenon gas was detected. The office of the Director of National Intelligence Public Affairs announced that "radioactive debris" was then detected two days after the test. The IMS station at Yellow Knife, Canada detected enhanced levels of Xe-133 12 days later proving that the event was a nuclear explosion. The high signal-to-noise ratio shows that the detection threshold level is much less than $0.6 \mathrm{kt}$. The data from four 1998 underground chemical tests at a distance of $289 \mathrm{~km}$ was used by Richards and Kim to determine the threshold level of $0.002 \mathrm{kt}$ for that region, a factor of 50 below the NAS limit of $0.1 \mathrm{kt}$.

\section{CONCLUSIONS ON MONITORING PROGRESS SINCE 1999}

In the early 1990s, the CTBT monitoring was expected to have a 1-kt threshold, but technical advances have lowered this expected threshold to 0.1-kt, and lower in certain regions. The lowered threshold is not surprising since earlier studies predicted this trend as technology, analysis, and regional access improved. The National Academy of Sciences results were based on both teleseismic and regional monitoring, with additional capabilities from arrays. CTBT monitoring advances since 1999 are as follows:

The National Academy of Sciences CTBT study (discussed earlier) concluded that the fully completed IMS will reliably detect and identify underground nuclear explosions to $0.1 \mathrm{kt}$ in hard rock, anywhere in Asia, Europe, North Africa, and North America. For most of Europe, Asia, and Northern Africa, the detection threshold is in the range of 0.03-0.06 kt in hard rock, and in some locations to less than $0.01 \mathrm{kt}$ with arrays and regional seismology. An explosion in a cavity above 1-2 kt cannot be confidently hidden, and it could be hidden at that level only with great difficulty. Atmospheric nuclear explosions can be detected and identified above 0.5-1 kt. Underwater nuclear explosions in the ocean can be detected and identified to $0.001 \mathrm{kt}$ or lower. Nuclear explosions in the upper atmosphere and near space can be detected and identified for yields above $1 \mathrm{kt}$ to 100 million kilometers from Earth.

Arrays of seismographs (see section on Seismic Arrays) can detect and identify events to a threshold of $2-2.5 \mathrm{~m}_{\mathrm{b}}$ from over $2000 \mathrm{~km}$ away, corresponding to explosive yields less than $0.01 \mathrm{kt}$ for tamped explosions and less than $1 \mathrm{kt}$ for an explosion decoupled in a large cavity.

Regional monitoring with $\mathrm{P}_{\mathrm{n}}, \mathrm{L}_{\mathrm{g}}$, and coda waves (see Regional Seismology Monitoring) is encouraging. Regional spectra contain much more information than narrowband magnitudes. New algorithms, closer access, and seismic models enhance the ability to discriminate between seismic sources and improve location estimates below $3.5 \mathrm{~m}_{\mathrm{b}}$. Using old Soviet data taken $500-1500 \mathrm{~km}$ from Semipalatinsk Test Site, all but two tests over one ton were detected. Regional seismic data obtained near North Korea show that the regional-seismic threshold is $0.002 \mathrm{kt}$ for that region. 
Further conclusions are as follows:

- Seismic thresholds can be lowered by $0.25-0.5 \mathrm{~m}_{\mathrm{b}}$ if the 120 IMS auxiliary stations (see International Monitoring System) are operated and analyzed in near-real time. ${ }^{63}$ Additional primary stations could become array stations.

- IMS data could be shared with the Global Seismic Network and other relevant seismic stations (discussed further in International Monitoring System), increasing available data from close-in sites, and improving CTBTO analysis with additional seismic experts.

- Correlation detection (see Seismic Arrays) can lower thresholds by 0.5-1.0 $\mathrm{m}_{\mathrm{b}}$. This approach is extremely useful for former test sites and is being extended to earthquake data, such as the 1997 Kara Sea event. It will take a decade to implement this approach much more widely.

- Cross-correlation (see Seismic Arrays) of seismic waveforms can reduce location uncertainties in seismically active regions by a factor of 10 to 100, as compared to estimates based on arrival times of seismic waves. Additional work over the next decade should enhance this approach.

- Radionuclide detection (see Radionuclide Monitoring) is an order of magnitude better than expected by using the Automatic Radioxenon Sampler Analyzer (ARSA) and the Radionuclide Aerosol Sampler and Analyzer (RASA).

- Interferometric Synthetic Aperture Radar (see Space-Based, Interferometric Synthetic Aperture Radar) can, under certain conditions, measure subsidence after a nuclear test with an accuracy of $0.2-0.5 \mathrm{~cm}$ and with location accuracy of $100 \mathrm{~m}$. InSAR can discriminate between earthquakes and explosions on the basis of the symmetry of the subsidence pattern. The detection threshold for InSAR is less than $1 \mathrm{kt}$ at $500 \mathrm{~m}$ depth if prior SAR data is available. Without prior SAR data, the InSAR threshold is above $20 \mathrm{kt}$. InSAR and SAR can detect test-site activity. Seismic data can be used to direct InSAR measurements.

- Cooperative monitoring (see Cooperative Monitoring at Test Sites) near test sites can detect yields less than $10 \mathrm{~kg}$ by using passive-seismic, infrasound, EMP, and video sensors. Dosimeters placed two meters from experiments can detect fission and fusion yields of less than 1 gram-equivalent, without revealing nuclear secrets.

- Open Skies flights could be extended to more nations to enhance their ability to participate more fully.

\section{NOTES AND REFERENCES}

1. D. Hafemeister, "Effective Verifiability of the CTBT," submitted to Arms Control Today. 
2. National Academy of Sciences, Technical Issues Related to the Comprehensive Nuclear Test Ban Treaty (Washington: National Academy Press, 2002). J. Holdren (chair), H. Agnew, R. Garwin, R. Jeanloz, S. Keeny, C. Larson, A. Narath, W. Panofsky, P. Richards, S. Sack, A. Trivelpiece, staff J. Husbands and D. Hafemeister.

3. E. Husebye and A. Dainty, ed., Monitoring a Comprehensive Test Ban Treaty (Boston: Kluwer Academic, 1995). Office of Technology Assessment, Seismic Verification of Nuclear Testing Treaties and The Containment of Underground Nuclear Explosions (Washington, OTA, 1988, 1989).

SRR, Proceedings of the Annual Seismic Research Review: Ground-based Nuclear Explosion Monitoring Technologies, SRR-27 (LA-UR-05-6407, 2005), SRR28 (LA-UR-06-5471, 2006), (Los Alamos: NNSA/AFTAC). Also, https://www.nemre. nnsa.doe.gov/cgi-bin/prod/researchreview/index.cgi, www.monitoring.llnl.gov, www.ees. lanl.gov Bulletin of the Seismological Society of America, http://www.seismosoc.org/ meetings/meetings.html. Pure and Applied Geophysics 158 (2001): (1-2) Source Location; (7) Regional Wave Propagation and Crustal Structure; (8) Surface Waves; (11) Source Processes and Explosion Yield Estimates. Ibid. 159 (2002): (4) Seismic Event Discrimination and Identification; (5-6) Data Processing and Infrasound.

4. National Research Council, Research Required to Support CTBT Monitoring (Washington: NRC, 1997): 14-15.The magnitudes for 1-kt and 150-kt tests at the former test sites are as follows:

NTS (3.87, 5.74), STS(4.45, 6.12), NZTS (4.32, 5.97), Lop Nor (4.3, 5.93), Mururoa $(4.5,6.04)$.

5. L. R. Sykes, "Four Decades of Progress in Seismic Identification Help Verify the CTBT," EOS Transactions of the American Geophysical Union 83 (29 October 2002): 497-500.

6. M. Fisk, D. Jepsen, and J. R. Murphy, "Experimental Seismic Event-screening Criteria at the Prototype International Data Center," Pure and Applied Geophysics 159 (2002): 865-888. There is an offset of $0.4 \mathrm{~m}_{\mathrm{b}}$ for earthquakes (but not for explosions), between U.S. National Earthquake Information Center (NEIC/USGS) and the Provisional IDC $($ PIDC/CTBTO $), m_{b}($ NEIC $)=m_{b}($ PIDC $)+0.4$ and $\mathrm{M}_{\mathrm{S}}(\mathrm{NEIC})=\mathrm{M}_{\mathrm{S}}(\mathrm{PIDC})+0.1$. Because there is no offset for explosions, this has little effect on NAS estimates for yield thresholds. J. P. Granville, P. G. Richards, W. Kim, and L. R. Sykes, "Understanding the Differences between Three Teleseismic $\mathrm{m}_{\mathrm{b}}$ Scales," Bulletin of the Seismological Society of America 95 (5) (2005): 1809-1824.

7. L. R. Sykes and J. F. Evernden, "Verification of a Comprehensive Test Ban Treaty," Scientific American 247 (October 1982): 47-55.

8. L. Sykes, J. Evernden, and I. Cifuentes, "Seismic Methods for Verifying Nuclear Test Bans," Amer. Instit. Physics Conf. Series 104 (1983), ed. D. W. Hafemeister and D. Schroeer: 85-133.

9. J. F. Evernden and C. B. Archambeau, "Some Seismological Aspects of Monitoring a CTBT," Arms Control Verification (Washington: Pergamon, 1986), ed. K. Tsipis, D. Hafemeister, and P. Janeway: 223-263.

10. W. J. Hannon, "In-country Seismic Stations for Monitoring Nuclear Test Bans," Nuclear Weapon Tests, ed. J. Goldblat and D. Cox (Oxford Univ. Press, 1988), 191-207. W. J. Hannon, "Seismic Verification of a Comprehensive Test Ban," Science 227 (1985): 251-257.

11. Office of Technology Assessment, Seismic Verification of Nuclear Testing Treaties (Washington: OTA, 1988).

12. J. P. Claassen, J. Unger, and W. Leith, "Performance Estimates of a Global Network of Open Stations," IRIS Newsletter 12 (3) (Washington, Incorporated Research Institution for Seismology, 1993): 1-3, 7. 
13. CTBT, Annual Report 2006 (Vienna: CTBTO, 2007): 37.

14. Ibid.

15. Annex 2 of the Protocol: For events detected by the International Monitoring System seismic component, the following parameters, inter alia, may be used: location of the event; depth of the event; ratio of the magnitude of surface waves to body waves; signal frequency content; spectral ratios of phases; spectral scalloping; first motion of the P-wave; focal mechanism; relative excitation of seismic phases; comparative measures to other events; and groups of events, and regional discriminants where applicable.

16. J. R. Murphy, "Initial Development of the IDC $\mathrm{M}_{\mathrm{S}} / \mathrm{m}_{\mathrm{b}}$ Event Screening Criteria, IDC Technical Experts Meeting on Event Screening" (Arlington, VA: SAIC Corp., October 2005). Event recalibration gives $M_{S}=1.25 m_{b}-3.00$ for Nevada Test Site and $M_{S}=1.25$ $\mathrm{m}_{\mathrm{b}}-3.50$ for Semipalitinsk Test Site.

17. J. R. Murphy et al., "Calibration of IMS stations in Central and Eastern Asia for Improved Seismic Event Location,” Bull. Seismological Society America 95(4), (2005): 1535-1560. O. Meier, "Hard Cases Stymie Test Ban Treaty," Arms Control Today 35 (November 2005): 30-32.

18. R. Butler et al., "The Global Seismographic Network Surpasses Its Design Goal," EOS 85 (June 2004): 225-229. Global Seismographic Network (IRIS July 2005).

19. T. Lay et al., "Global Seismic Network Design Goals Update 2002" (IRIS, August 26, 2002).

20. K. Aki and P. Richards, Quantitative Seismology (Sausalito, CA: University Science Books, 2002): 647.

21. V. Khalturin, T. Rautian, and P. Richards, "A Study of Small Magnitude Seismic Events during 1961-1989 On and Near the Semipalatinsk Test Site, Kazakhstan," Pure and Applied Geophysics 158 (2001): 143-171. Also NAS-CTBT: 39.

22. E. Husebye and A. Dainty, ed., Monitoring a Comprehensive Test Ban Treaty (Boston: Kluwer Academic, 1995. Also SRR-27.

23. J. R. Murphy and B. W. Barker, "Application of Network-averaged Teleseismic PWave Spectra to Seismic Yield Estimates of Underground Nuclear Explosions," Pure and Applied Geophysics 158 (2001): 2123-2171.

24. M. Fisk, T. Lay, and S. Taylor, "Modeling and Empirical Research on Energy Partitioning of Regional Seismic Phases used for Explosion Monitoring," SRR-27: 539-549, and "Modeling and Empirical Research on Energy Partitioning of Regional Seismic Phases Used for Explosion Monitoring," SRR-28: 580-589.

25. D. F. Harris, "Ground Truth Collection for Mining Explosions in Northern Fennoscandia and Northwestern Russia," SRR-27: 31-41.

26. K. Mayeda et al., "Stable and Transportable Regional Magnitudes Based on CodaDerived Moment-Rate Spectra, Bull. Sesimological Soc. America 93 (2003): 224-239. W. S. Phillips et al., "Calibration for Coda-Based Magnitude and Yield," SRR-26 (2004): 449-456.

27. I. Tibuleac et al., "Predicting Explosion Generated $\mathrm{S}_{\mathrm{n}}$ and $\mathrm{L}_{\mathrm{g}}$ Coda Using Synthetic Seismograms,"SRR-27: 214-221.

28. H. T. Bungun et al., "Energy Partitioning for Seismic Events in Fennoscandia and NW Russia," SRR-27: 529-538.

29. M. Fisk, T. Lay, and S. Taylor, "Modeling and Empirical Research on Energy Partitioning of Regional Seismic Phases used for Explosion Monitoring," SRR-27: 539549 . 
30. Surface wave models: M. Pasyanos, W. Walter, and S. Hazler, "A Surface Wave Dispersion Study of the Middle East and North Africa for Monitoring the CTBT," J. Pure \& Applied Geophysics 158 (2001): 1445-1474. M. Pasyanos et al., "Geophysical Model Applications for Monitoring," SRR-27: 142-151. W. Rodi and D. Reiter, "Development of a Joint Regional Body and Surface Wave Tomography Method," SRR-27: 178-188. van der Lee et al., "Towards a Comprehensive Seismic Velocity Model for the Broader AfricaEurasia Collision Region to Improve Nuclear Explosion Monitoring," SRR-27: 232-241. M. Fisk, T. Lay, and S. Taylor, "Modeling and Empirical Research on Energy Partitioning of Regional Seismic Phases used for Explosion Monitoring," SRR-27: 539-549. M. Pasyanos et al., "The Use of Geophysical Models for Nuclear Explosion Monitoring," SRR-28: 176-185.

31. P. G. Richards et al., "The Applicability of Modern Methods of Earthquake Location," Pure and Applied Geophysics 163 (2006): 351-372.

32. F. Ringdal et al., "Research in Regional Seismic Monitoring," SRR-27: 423-432 and "Adaptive Waveform Correlation Detectors for Arrays," SRR-28: 444-454.

33. F. Ringdal, S. Gibbons, and D. Harris, "Adaptive Waveform Correlation Detectors for Arrays: Algorithms for Autonomous Calibration," SRR-27: 413-422.

34. Pure and Applied Geophysics 159 (5-6) (2002): Data Processing and Infrasound. N. Brachet and J. Coyne, "Current Status of Infrasound Data Processing at the International Data Centre," SRR-28: 873-881.

35. F. Ringdal et al. "Basic Research on Seismic and Infrasonic Monitoring of the European Artic," SRR-28: 1017-1027.

36. D. R. Christie, B. L. Kennett, and C. Tarlowski, "Detection of Regional and Distant Atmospheric Explosions at IMS Infrasound Stations," SRR-27: 817-827.

37. H. F. Bass and F. D. Shields, "The Use of Arrays of Electronic Sensors to Separate Infrasound from Wind Noise," SRR-26: 601-607.

38. M. A. Zumberge et al., "An Optical Fiber Infrasound Sensor: A New Lower Limit on Atmospheric Pressure Noise between 1 and $10 \mathrm{~Hz}$," J. Acoustical Society America 113 (2003): 2474-2479. K. Walker, M. A. Zumberge, J. Berger, and M. Hedlin, "An Improved Method for Determining Infrasound Back Azimuth with Optical Fiber Sensors," SRR27: 855-865, and "Determining Infrasound Phase Velocity Direction with a Three-Arm OFIS," SRR-28: 947-956.

39. Pure and Applied Geophysics 159(3) (2001): Hydroacoustic. F. Graeber, J. Coyne, and E. Tomuta, "The Current Status of Hydroacoustic Data Processing at the International Data Centre," SRR-28: 717-724.

40. NAS-CTBT: 52.

41. Horizontal ocean wave energy ( $T$ phase) couples to ground motion on islands, which is measured seismically.

42. J. J. Pulli and Z. M. Upton, "Azimuthal Dependence on Hydroacoustic Blockage at Diego Garcia and Implications for Discrimination," SRR-27: 740-748.

43. E. Matzel, A. Ramirez, and P. E. Harben, "Model-Based Hydroacoustic Blockage Assessment and Development of an Explosive Source Database," SRR-27: 733739.

44. NAS-CTBT: 53.

45. T. W. Bowyer et al., "Field Testing of Collection and Measurement of Radioxenon for the Comprehensive Test Ban Treaty," J. Radioanalytical Nuclear Chemistry 240 (1) (1999): 109-122. This was enhanced by using a delayed coincident gate for the conversion electrons. 
46. S. R. Biegalski and O. A. Ezekoye, "Design of Aerosol Sampler to Remove Radon and Thorium Progeny Interference from Aerosol Samples for Nuclear Explosion Monitoring," SRR-27: 761-769.

47. Li Bin, "Analysis of Fission Products: A Method for Verification of a CTBT During On-site Inspections," Science and Global Security 7 (1998): 195-207.

48. P. Vincent et al., "New Signatures of Underground Nuclear Tests Revealed by Satellite Radar Interferometry," Geophysical Research Letters 30 (2003): 2141-2145. S. M. Buckley, P. Vincent, and K. Gudipati, "Next Generation InSAR Ground-Truth Data and Techniques," SRR-2004 (2004): 247-256. S. M. Buckley, P. Vincent, and D. Yang "New Ground-Truth Capability from InSAR Time Series Analysis," SSR-2005 (2005): 898-906.

49. SAR data from McDonald, Dettweiler, \& Associates (gs.mdacorporation.com/ products/sensor/radarsat), software from PCI Geomatics (www.pcigeomatics.com).

50. D. Massonnet and K. L. Feigl, "Radar Interferometry and Its Application to Changes in the Earth's Surface," Review of Geophysics 36(4) (1998): 441-500. P. A. Rosen et al., "Synthetic Aperture Radar Interferometry," Proceedings of the IEEE 88(3), (2000): 333-382.

51. J. Murphy, ibid. 241-244. Large-Scale, Open-Air Explosive Detonation, Divine Strake, at the Nevada Test Site (DOE/EA-1550, November 2005): 1-8.

52. G. Rennie, "Monitoring Earth's Subsidence from Space," Science and Technology Review (Lawrence Livermore National Laboratory, April 2005): 4-11.

53. CTBT-Negotiator S. J. Ledogar, SFRC (1999): 16.

54. S. L. Jones and F. N. von Hippel, "Transparency Measures for Subcritical Experiments under the CTBT," Science and Global Security 6 (1997): 291-310. F. N. von Hippel and S. L. Jones, “Take a Hard Look at Subcritical Tests," Bulletin of Atomic Scientists 52 (November/December 1996): 44-47.

55. S. Drell et al., Subcritical Experiments (McLean, VA: JASON, Mitre Corp., 1997).

56. J. Zucca, et al., "Signatures of Testing: On-Site Inspection Technologies," in Monitoring a Comprehensive Test Ban Treaty: 123-134.

57. Ibid. 126.

58. P. R. Richards and W. Y. Kim, "Testing the Nuclear Test-Ban Treaty," Nature 389 (October 23, 1997): 781-782; G. van der Vink et al., "False Accusations, Undetected Tests and Implications for the CTB Treaty," Arms Control Today 28 (May 1998): 7-13.

59. F. Ringdal et al., "Research in Regional Seismic Monitoring," SRR-2005: 423-432.

60. B. Barker et al., "Monitoring Nuclear Tests," Science 281 (25 September 1998): 1967-1968.

61. The $0.03 \mathrm{kt}$ is an upper value due to the lack of any signal at Nilore on May 13; it represents the Nilore detection threshold on May 13.

62. P. Richards and W. Y. Kim, "Seismic Signature," Nature Physics 3 (January 2007): 4-6. R. L. Garwin and F. N. von Hippel, "Deconstructing North Korea's October 9 Nuclear Test," Arms Control Today 38 (November 2006): 14-16. W. Y. Kim and P. Richards, "North Korean Nuclear Test: Seismic Discrimination at Low Yield," EOS 88 (April 3, 2007): 157-161.

63. NAS-CTBT Study: 49. 